\title{
Electrically Active Diurnal Pulses in Hurricane Harvey (2017)
}

\author{
Sarah D. Ditchek, Kristen L. Corbosiero, Robert G. Fovell, And John Molinari \\ Department of Atmospheric and Environmental Sciences, University at Albany, State University of \\ New York, Albany, New York
}

(Manuscript received 24 January 2020, in final form 5 March 2020)

\begin{abstract}
Recent research has found that diurnal pulses are ubiquitous features of tropical cyclones. To gain further insight into the characteristics of these pulses, a case study of an electrically active (ACT) cooling pulse and an off-the-clock ACT cooling pulse that occurred in Hurricane Harvey (2017) was conducted. Using GridSat-B1 IR brightness temperatures, World Wide Lightning Location Network (WWLLN) lightning data, the 85-91GHz channels on microwave satellite imagers, and Level-II Doppler radar reflectivity data from WSR-88D stations (i.e., NEXRAD), these pulses were found to share many similar characteristics: both propagated outward on the right-of-shear side of Harvey and were associated with elevated cloud ice content and high reflectivity. Additionally, using HRRR model output, both pulses were found to be associated with 1) column-deep total condensate, 2) a surface cold pool, 3) an overturning circulation, and 4) an enhanced low-level jet. These characteristics are similar to those found in tropical squall lines, supporting the tropical squall-line interpretation of diurnal pulses put forth in recent studies. A hypothesis for ACT pulse initiation was then introduced, tested, and confirmed: inner rainbands that propagated outward into a more favorable environment for deep convection reinvigorated into ACT pulses that had tropical squall-line characteristics.
\end{abstract}

\section{Introduction}

Dunion et al. (2014) took 6-h IR brightness temperature differences of Atlantic basin major hurricanes from 2001 to 2010. In doing so, they found an area of cooler cloud tops (relative to $6 \mathrm{~h}$ prior) that routinely propagated outward from the $200-\mathrm{km}$ radius beginning around 0400-0800 LT. These cooler cloud tops had a propagation speed of about $5-10 \mathrm{~m} \mathrm{~s}^{-1}$, so that by 1500 $1800 \mathrm{LT}$, they were around the $500-\mathrm{km}$ radius. They also found that these cooler cloud tops (negative values in the difference fields) were often trailed by warmer cloud tops (positive values in the difference fields). They defined this propagating feature as a "diurnal pulse" and created a 24-h conceptual clock that identified around which radius the pulse would be located based on local time (LT).

To understand tropical cyclone diurnal pulse frequency, structure, and characteristics, Ditchek et al. (2019a) generalized and expanded the results of Dunion et al. (2014) by creating a 36-yr climatology of Atlantic basin diurnal pulses that had similar temporal phasing as

Corresponding author: Sarah D. Ditchek, sarahditchek@gmail.com the Dunion et al. (2014) clock. As in Dunion et al. (2014), Ditchek et al. (2019a) used IR brightness temperatures to create 6-h IR brightness temperature difference fields, and pulses of cooler cloud tops were defined objectively by determining critical thresholds for the magnitude of the IR brightness temperature differences and areal coverage of cold cloud tops. The metric identified days with "cooling pulses", similar to those documented by Dunion et al. (2014), and days without cooling pulses. For some of the days without cooling pulses, locally warmer cloud tops that propagated outward at a similar time and speed as their cooling cloud top counterparts were discovered. These "warming pulses," a previously undiscovered pulse type, were then also objectively defined using thresholds for the magnitude of the IR brightness temperature differences and areal coverage of warm-cloud tops. Cooling and warming pulses were then divided, based on their longevity, into long-lived pulses $(\geq 9 \mathrm{~h})$ and short-lived pulses (3-6h). Therefore, each storm day was given a pulse-type classification: 1) long-lived cooling pulse (LLCP), 2) short-lived cooling pulse (SLCP), 3) long-lived warming pulse (LLWP), 4) short-lived warming pulse (SLWP), or 5) no pulse (NP). One key result of 
Ditchek et al. (2019a) was that diurnal cooling and warming pulses were near-ubiquitous features of tropical cyclones, present $88 \%$ of the time.

Taking IR brightness temperature differences only depicts the tendencies at cloud top. Dunion et al. (2014), however, showed that diurnal pulses might be associated with deep convection. For example, using $89-\mathrm{GHz}$ microwave satellite imagery, they showed that Hurricane Emily (2005) and Hurricane Felix (2007) had diurnal pulses that were associated with elevated cloud ice content and, therefore, possibly deep convection (cloud ice is indicated by warm colors in their Figs. 2c,d and $5 c, d)$. Later, Dunion et al. (2019) used the highly realistic "hurricane nature run" of Nolan et al. (2013) to study diurnal pulses. In doing so, they found that pulses were associated with enhanced vertical velocities and elevated total condensate, along with trailing downdrafts and suppressed moisture, signatures of a cold pool. They, therefore, stated that their results supported a tropical squall-line explanation of diurnal pulses.

Since Dunion et al. $(2014,2019)$ found that diurnal pulses could be column-deep, Ditchek et al. (2019b) stratified the 36-yr climatology of Ditchek et al. (2019a) into pulses that were and were not associated with deep convection using World Wide Lightning Location Network (WWLLN) lightning data from 2005 to 2017, as lightning has been found to be a sufficient, but not necessary, proxy for deep convection in tropical cyclones (Corbosiero and Molinari 2002, 2003; Abarca et al. 2011; Stevenson et al. 2016, 2018). They identified electrically active (ACT), quasi-electrically active (QUASI), and electrically inactive (INACT) pulses based on an objective metric that incorporated lightning flash density, areal coverage, and longevity within a pulse. It was found that ACT pulses occurred around $61 \%$ of the time, primarily when pulses propagated outward on the right-of-shear side of the storm, the dominant quadrant for outer-rainband lightning activity (Corbosiero and Molinari 2002, 2003; Stevenson et al. 2016). Interestingly, ACT warming pulses were associated with off-the-clock ${ }^{1}$ ACT cooling pulses that propagated outward ahead of the warming pulse. The propagation speed of ACT cooling pulses, ACT warming pulses, and INACT cooling pulses offered support to the gravity wave interpretation of diurnal pulses proposed in the literature (Navarro et al. 2017; O'Neill et al. 2017; Ruppert and O'Neill 2019; Evans and Nolan 2019) and to the Dunion et al. (2019) result that pulses take on tropical squall-line characteristics after propagating away from the inner core. The INACT warming pulses, however, had a

\footnotetext{
${ }^{1}$ A pulse being "off-the-clock" means that it did not follow the Dunion et al. (2014) diurnal clock schematic.
}

propagation speed that did not support the gravity wave interpretation of diurnal pulses. Additionally, as INACT warming pulses were not associated with convection, the tropical squall-line interpretation was found to be incomplete.

While Ditchek et al. (2019a,b) answered questions about the frequency and structure of tropical cyclone diurnal pulses, they relied on composites and did not examine the thermodynamic and kinematic properties of pulses. Therefore, it was not possible to gain further insight into pulse characteristics, including whether pulses behave like tropical squall lines (Dunion et al. 2019) and their potential initiation mechanisms. Since the literature lacks case studies of observed diurnal pulses, this paper focuses on two representative $\mathrm{ACT}^{2}$ pulses present in Hurricane Harvey (2017): an ACT cooling pulse and an ACT warming pulse. Since Ditchek et al. (2019b) found that ACT warming pulses were preceded by an off-the-clock ACT cooling pulse, most of the results discussed in this paper will focus on comparing the ACT cooling pulse to the off-the-clock ACT cooling pulse.

The aim of this paper is threefold: 1) to document the evolution of the two representative ACT pulses, 2) to evaluate whether these pulses behaved like tropical squall lines, and 3) to identify their initiation mechanisms. Data used are detailed in section 2. Section 3 details how the two representative pulse days were selected. Section 4 documents the plan-view evolution of Harvey's 6-h IR brightness temperature differences and associated lightning, supplemented by $85-91-\mathrm{GHz}$ microwave and radar reflectivity imagery for both ACT pulse days. To better understand the thermodynamic and kinematic properties of the ACT pulses present in Harvey and determine whether they behaved like tropical squall lines, forecasts from the High-Resolution Rapid Refresh (HRRR; Benjamin et al. 2016) model developed by NOAA's Earth System Research Laboratory (ESRL) and run by NCEP's Environmental Modeling Center (EMC) were used to further study the observed diurnal pulses (section 5). From results gathered, a hypothesis for ACT pulse initiation was formed and tested (section 6). Finally, section 7 provides a summary and areas for future work.

\section{Data}

\section{a. Observations}

Four times daily location and intensity data over Harvey's lifetime from 0600 UTC 16 August to 1200 UTC

\footnotetext{
${ }^{2}$ The reason behind the selection of just these two pulse types will be described in section 3 .
} 
2 September 2017 were obtained from the Hurricane Database (HURDAT2; Landsea and Franklin 2013) and were linearly interpolated to a temporal resolution of $3 \mathrm{~h}$. For each storm time, the $p=200-850-\mathrm{hPa}, r=0$ 500-km developmental Statistical Hurricane Intensity Prediction Scheme (SHIPS; DeMaria and Kaplan 1994, 1999; DeMaria et al. 2005) shear magnitude (kt; $1 \mathrm{kt} \approx$ $0.5144 \mathrm{~m} \mathrm{~s}^{-1}$ ) and direction (degrees) were also retrieved, linearly interpolated to a temporal resolution of $3 \mathrm{~h}$, and converted to $\mathrm{m} \mathrm{s}^{-1}$.

Next, the 3-h temporal resolution and $0.07^{\circ} \times 0.07^{\circ}$ horizontal resolution GridSat-B1 IR brightness temperatures (Knapp et al. 2011) were extracted and centered on each storm time, yielding 139 storm-centered grids over 18 storm days. The 6-h IR brightness temperature differences $\left(T_{0}-T_{-6} \mathrm{~h}\right)$ were then computed on the storm-centered $0.07^{\circ} \times 0.07^{\circ}$ resolution grid every $3 \mathrm{~h}$.

Lightning flash locations $\pm 1.5 \mathrm{~h}$ of each storm time were obtained from WWLLN and binned to a stormcentered, $0.07^{\circ} \times 0.07^{\circ}$ grid, matching the GridSat-B1 resolution. As described in Ditchek et al. (2019b), in order for the yearly WWLLN lightning density to match the lightning density climatology of the spaceborne Optical Transient Detector (OTD) and the Lightning Imaging Sensor (LIS) on board the Tropical Rainfall Measuring Mission (TRMM) satellite, adjustment factors are applied to the WWLLN data. These adjustment factors account for the increase in sensors and improved detection algorithms, and, therefore, detection efficiency over time (Rodger et al. 2009; Abarca et al. 2010; DeMaria et al. 2012; Stevenson et al. 2018). Therefore, the 2017 adjustment factor of 3.6 that was used in Ditchek et al. (2019b) was applied to the WWLLN data.

Since IR brightness temperatures only depict the temperatures at cloud top, to view the areas of tropical cyclones with deep convective features (e.g., the eyewall, rainbands, and perhaps diurnal pulse), the 85-91$\mathrm{GHz}$ channels on microwave satellite imagers were used. In these channels, areas of deep convection have low brightness temperatures (warm colors) due to ice scattering, while the ocean and low-level, moist air have high brightness temperatures (cool colors; Hawkins and Velden 2011). The 85-91-GHz channels from four sources were obtained: 1 ) the Special Sensor Microwave Imager (SSM/I; F-15) on board the Defense Meteorological Satellite Program (DMSP) satellites, 2) the Special Sensor Microwave Imager/Sounder (SSMIS; F-16,-17, and -18) on board the DMSP satellites, 3) the Advanced Microwave Scanning Radiometer 2 (AMSR2) on board the GCOM-W1 satellite, and 4) the Advanced Microwave Sounding Unit-B (AMSU-B) on board the NOAA-18 satellite. Images were retrieved from the Naval Research Laboratory Monterey Tropical Cyclones web page (http://www.nrlmry.navy.mil/TC.html) and were modified for aesthetic purposes.

Level-II Doppler radar reflectivity data from WSR88D stations (i.e., NEXRAD) were also used to visualize the structure of the pulses underneath the cloud top. The reflectivity data has an approximately 5-min temporal resolution and around a 1-km spatial resolution. NOAA's Weather and Climate Toolkit (https:// www.ncdc.noaa.gov/wct/) was used to extract reflectivity data at the lowest elevation angle every $3 \mathrm{~h}$, to match the temporal resolution of GridSat-B1, and every $30 \mathrm{~min}$, to show finer-resolution features over a select period of time (section 6b). Stations accessed included Corpus Christi (KCRP) and Houston (KHGX).

\section{b. HRRR model analyses}

To better understand the characteristics of diurnal pulses, version 2 of the HRRR, archived by the University of Utah MesoWest HRRR (Blaylock et al. 2017), was used to supplement the 6-h IR brightness temperature differences, lightning data, 85-91-GHz microwave imagery, and reflectivity imagery.

The HRRR uses the Advanced Research Weather Research and Forecasting Model (WRF-ARW) as its core. Its grid is centered over the contiguous United States on a Lambert Comformal projection, with initial and boundary conditions from the 13-km Rapid Refresh (RAP) model that covers the entirety of North America. The horizontal resolution of the HRRR is $3 \mathrm{~km}$. This high spatial resolution made it ideal to use as the diurnal pulse is around $75-200-\mathrm{km}$ wide (Ditchek et al. 2019a, Figs. 4 and 5); thus, at least 25 model grid points would span the pulse. The HRRR is run every hour, producing $0-18$-h forecasts. More information on the HRRR can be found in Benjamin et al. (2016).

Since prior to each initialization, available observations, including reflectivity, are assimilated ( $\mathrm{Wu}$ et al. 2002; James and Benjamin 2017), it is expected that the HRRR should be able to reproduce the diurnal pulses in Harvey. In essence, therefore, the HRRR is used to accomplish retrievals of fields that cannot be directly sensed by, or easily obtained from, observations.

The first time when Harvey's center was $400 \mathrm{~km}$ from the southern boundary of the HRRR was 0600 UTC (0000 LT) 26 August. From that time until Harvey made its final landfall at 0800 UTC 30 August (so as not to include times when Harvey was transitioning from a tropical to an extratropical system; Blake and Zelinsky 2017), forecast hour 0 (i.e., the analysis) was retrieved, as 
it was the only hour archived for three-dimensional fields. Fields accessed included simulated IR brightness temperature (K), total condensate (TOTCOND; $\mathrm{g} \mathrm{kg}^{-1}$ ), temperature (TMP; K), convective available potential energy (CAPE; $\mathrm{J} \mathrm{kg}^{-1}$ ), as well as zonal and meridional winds, which were transformed into radial wind (RADWND; $\mathrm{ms}^{-1}$ ) and tangential wind (TANWND; $\mathrm{m} \mathrm{s}^{-1}$ ). Storm-centered fields were computed by centering each field on the smoothed mean sea level pressure (MSLP) minimum in the HRRR for each analysis time, where a 19-point moving average was used to achieve the smoothing. Tracking minimum MSLP, an integrated quantity, was found by Alland (2019) to find the storm center more accurately than other storm-centering methods such as those detailed in Nguyen et al. (2014).

\section{Selection of case study days}

While Harvey occurred over an 18-day period, there were only 16 full (0000-2300 LT) storm days. Using the objective metric from Ditchek et al. (2019a), each of these 16 storm days was given a pulse-type classification. Then, using the objective metric from Ditchek et al. (2019b), cooling and warming pulse days were classified based on their electric activity. For a concise view of the lifetime diurnal-pulse activity in Harvey, please see the appendix.

Since the HRRR was used to explore pulse types further, only days from 0600 UTC (0000 LT) 26 August to 0800 UTC (0200 LT) 30 August could be considered (as described in section 2b). The objective metrics identified that across those four days there were three ACT cooling pulses and one ACT warming pulse. For the purpose of this study, two representative days were selected: one of the days with an ACT cooling pulse (26 August) and the day with an ACT warming pulse (28 August).

These pulse days occurred after Harvey made its first landfall. Due to that landfall, during the first $3 \mathrm{~h}$ of the ACT cooling pulse day, Harvey rapidly weakened from a category 4 hurricane to a tropical storm. For the remainder of the day, the intensity was steady. The ACT warming pulse occurred while Harvey was stalled over, and just offshore of, the Texas coastline. Over that entire day, Harvey remained a tropical storm and did not experience any intensity fluctuations. Despite the structural changes that accompany rapid weakening and landfall, the objective metrics were still able to identify that ACT cooling and warming pulses occurred on these two days. Furthermore, as will be seen in sections 4 and 5, the evolution of both the ACT cooling and warming pulses were similar to the composite results of Ditchek et al. (2019b) (their Figs. 3 and 5), which did not include landfalling storms. This similarity is, perhaps, because the ACT cooling and warming pulses studied here mostly moved radially outward over the Gulf of Mexico rather than moving radially outward over land.

Therefore, while studying the impacts of landfall on diurnal pulse frequency and structure should be an area of future research, it does not appear as though Harvey's landfall drastically affected or modified these two pulses. It should be noted, however, that land interactions are occurring during the pulses investigated in this paper. Additionally, while similar analyses could be conducted for a different storm, in order to include the high temporal and spatial resolution reflectivity data, a storm that moved close to land would need to be selected.

\section{ACT cooling pulse}

The ACT cooling pulse occurred over the 24-h period beginning at 0600 UTC (0000 LT) 26 August. On this day, the shear was mostly southwesterly at $7.7 \mathrm{~m} \mathrm{~s}^{-1}$ on average, falling into the moderate-shear grouping, where moderate shear $\left(4.4-10.6 \mathrm{~m} \mathrm{~s}^{-1}\right)$ was defined as the interquartile range of the climatological distribution of shear values in Ditchek et al. (2019a).

\section{a. Observations}

The 6-h IR brightness temperature difference evolution with overlaid lightning for the ACT cooling pulse every $3 \mathrm{~h}$ from 0000 to $2100 \mathrm{LT}$, along with white circles that depict around where the pulse should be located following the Dunion et al. (2014) clock, is given in Fig. 1. The pulse began propagating outward around 0300 LT near the $200-\mathrm{km}$ radius, already coupled to lightning. It continued propagating outward through $1800 \mathrm{LT}$ when it was present beyond the $500-\mathrm{km}$ radius. The pulse propagated outward on the right-ofshear side of the storm, the dominant side for lightning activity outside of the inner core and the side often associated with ACT pulses (Ditchek et al. 2019b). Additionally, trailing the ACT cooling pulse were warming cloud tops.

The abundant lightning present suggests that the ACT cooling pulse was a column-deep feature. Therefore, it is not surprising that the corresponding 85-91-GHz microwave imagery showed the presence of elevated cloud ice content (i.e., possibly deepconvective clouds) in the ACT cooling pulse between 0300 and 1800 LT (Fig. 2). It was also not surprising that the pulse was seen in the reflectivity field between 0600 and 1200 LT when the amplitude of the 6-h IR brightness temperature differences was largest (Fig. 3). The trailing warming behind the ACT cooling pulse 


\section{ACT Cooling Pulse}

\section{GridSat-B1 6-h IR Brightness Temperature Differences}

(26 August 2017)
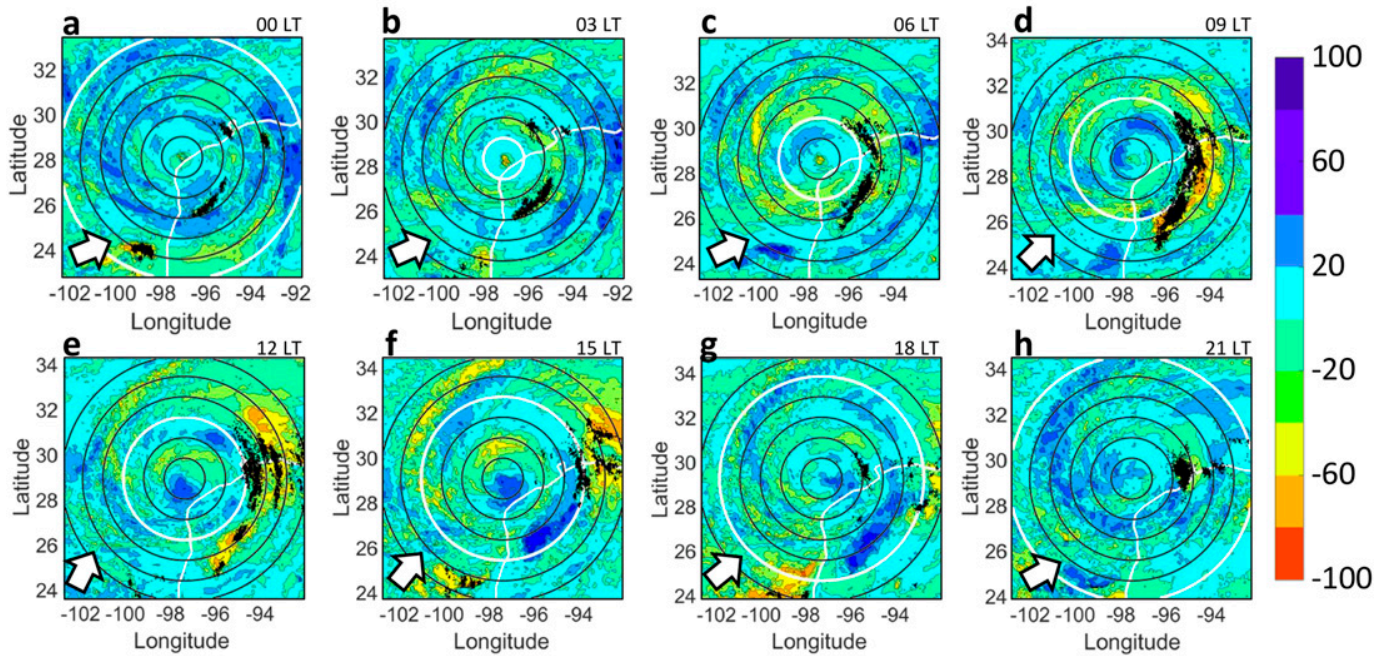

FIG. 1. A plan view of 6-h IR brightness temperature difference fields $\left({ }^{\circ} \mathrm{C}\right)$ at times closest to (a) 0000 , (b) 0300 , (c) 0600 , (d) 0900, (e) 1200, (f) 1500, (g) 1800, and (h) 2100 LT with overlaid lightning $\pm 1.5 \mathrm{~h}$ centered on the image time for the day when the ACT cooling pulse occurred. The shear direction is indicated by the white arrow at the bottom left of each plot. Black range rings are overlaid on each image every $100 \mathrm{~km}$ from $r=100-600 \mathrm{~km}$. White range rings indicate the radius around which the pulse should occur using the extended version of the Dunion et al. (2014) diurnal clock (Ditchek et al. 2019a, Fig. 2b). Note that the colorbar resembles the conventional IR brightness temperature scale, where warmer colors represent colder cloud tops and cooler colors represent warmer cloud tops.

\section{ACT Cooling Pulse}

\section{5-91 GHz Microwave Imagery (26 August 2017)}
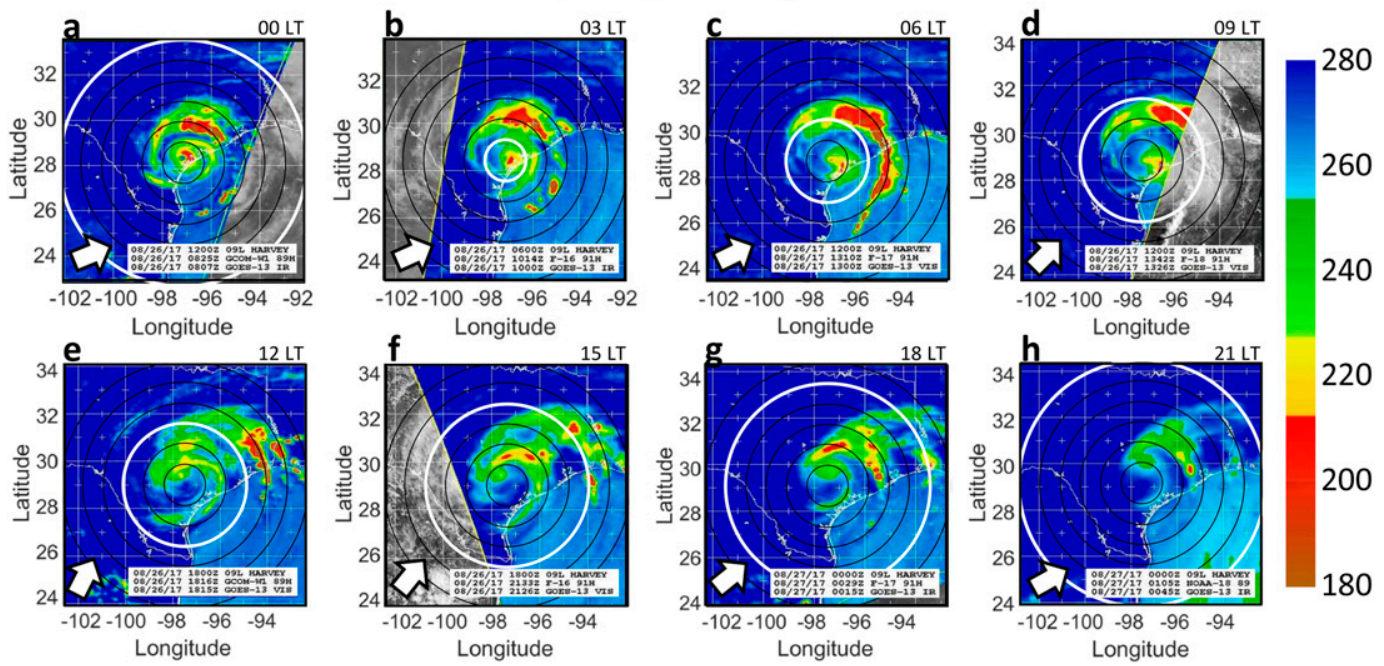

FIG. 2. As in Fig. 1, but for 85-91-GHz microwave imagery (K) without overlaid lightning. Images were retrieved from the Naval Research Laboratory Monterey Tropical Cyclones web page (http://www.nrlmry.navy.mil/ TC.html) and were modified for aesthetic purposes. 


\section{ACT Cooling Pulse}

\section{KCRP Reflectivity}

(26 August 2017)
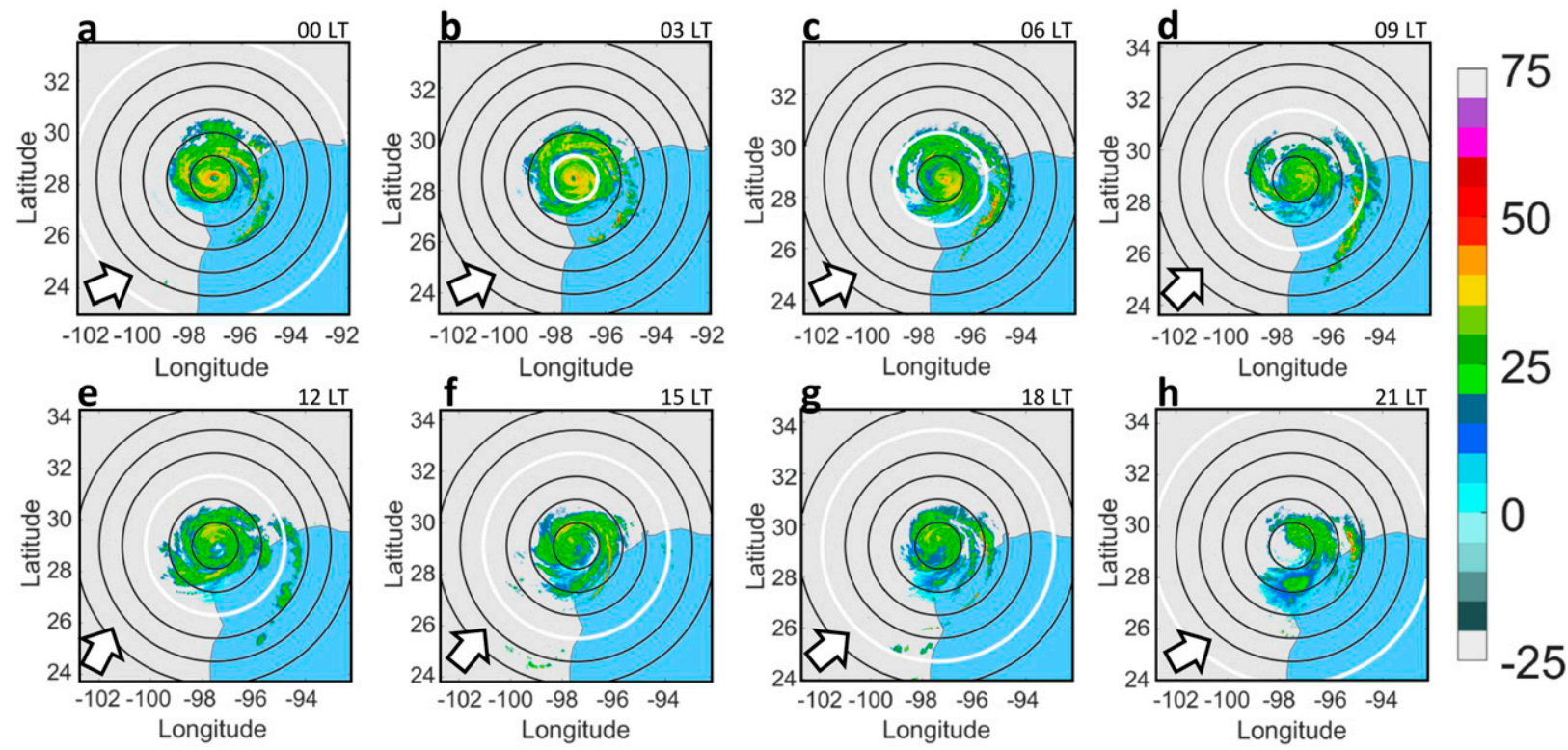

FIG. 3. As in Fig. 1, but for reflectivity (dBZ) without overlaid lightning.

was also detectable, associated with an absence of cloud ice (Fig. 2) and low reflectivity values (Fig. 3).

\section{b. Reproducibility of observed ACT cooling pulse}

The analyses of the 0600 UTC (0000 LT) 26 August0300 UTC (2100 LT) 27 August initializations of the HRRR were used to determine whether the ACT cooling pulse was reproduced by the model. The plan-view evolution of the 6-h simulated IR brightness temperature differences depicted an outward propagating pulse on the eastern side of the storm, as found in the observations (not shown). The associated azimuthally averaged, ${ }^{3}$ simulated, IR brightness temperatures and corresponding 6-h IR brightness temperature differences (Figs. 4a,b) depicted an on-the-clock, outward-propagating cooling pulse with trailing warming that had a similar timing and propagation speed as the ACT cooling pulse seen in the observations (Figs. 4c,d). The structures of the ACT cooling pulse in the HRRR and the observations were similar, with the maximum amplitude of the pulse peaking at outer radii. Finally, the HRRR also reproduced the cold cloud tops in the inner core that were present overnight (Figs. 4a,c). Therefore,

\footnotetext{
${ }^{3}$ The HRRR azimuthal averages were computed using a 3-km bin size, matching the HRRR resolution.
}

the HRRR was able to reproduce many aspects of the ACT cooling pulse.

\section{c. Thermodynamic and kinematic properties from the HRRR}

To depict the anomalous thermodynamic and kinematic properties associated with the ACT cooling pulse, anomalies from daily mean, sector-averaged cross sections were taken for total condensate, temperature, radial wind, and tangential wind (Fig. 5). ${ }^{4}$ By taking azimuthal averages over a sector rather than the entire storm, the resulting azimuthal averages focus on just the pulse and, due to its circular geometry, essentially run along the axis of the pulse. Here, sector averages were conducted over the eastern half of Harvey, as that was where the ACT cooling pulse was located (Fig. 1). For reference, a diagram of this sector is included in Fig. 5. For brevity, sector-averaged cross sections are shown every $6 \mathrm{~h}$, instead of $3 \mathrm{~h}$.

The ACT cooling pulse in the HRRR was associated with outward propagating, enhanced total condensate. At 0000 LT, enhanced total condensate was mostly concentrated at mid- to upper levels and was located

\footnotetext{
${ }^{4}$ Qualitatively similar results were found when taking 6-h differences instead of anomalies from the daily mean.
} 


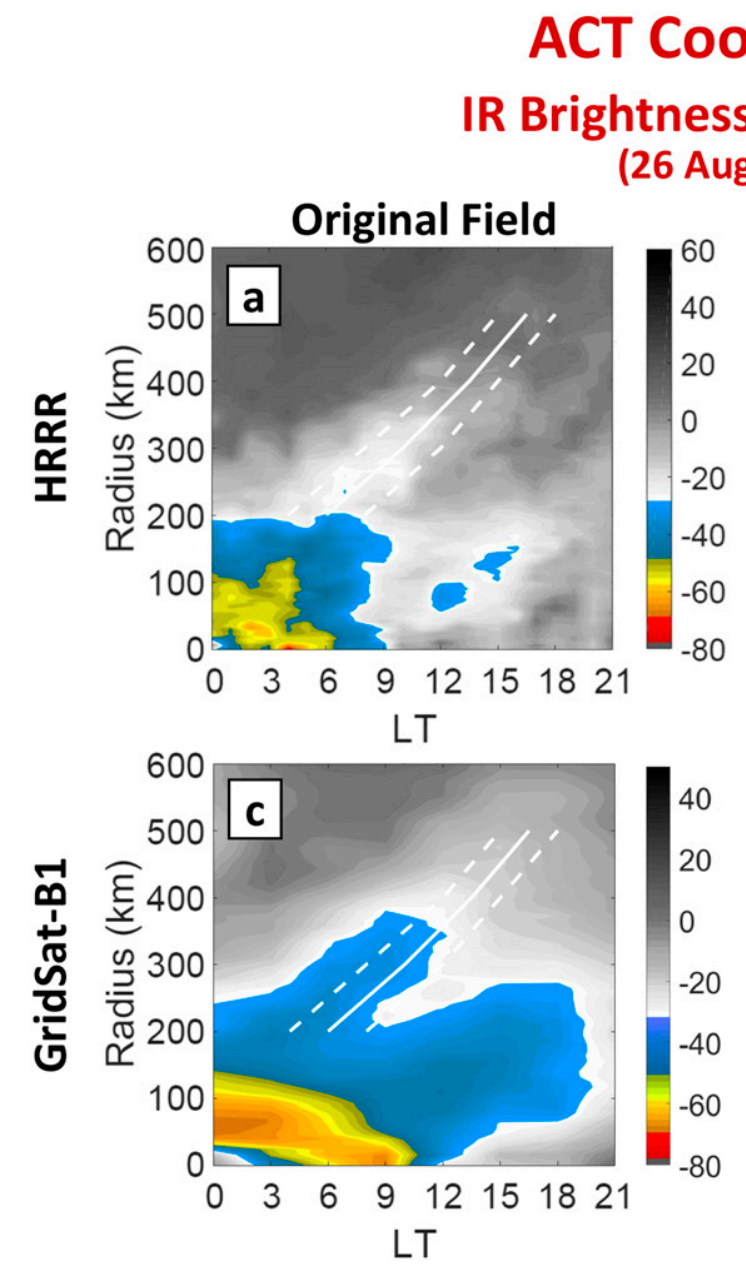

ACT Cooling Pulse

IR Brightness Temperatures

(26 August 2017)
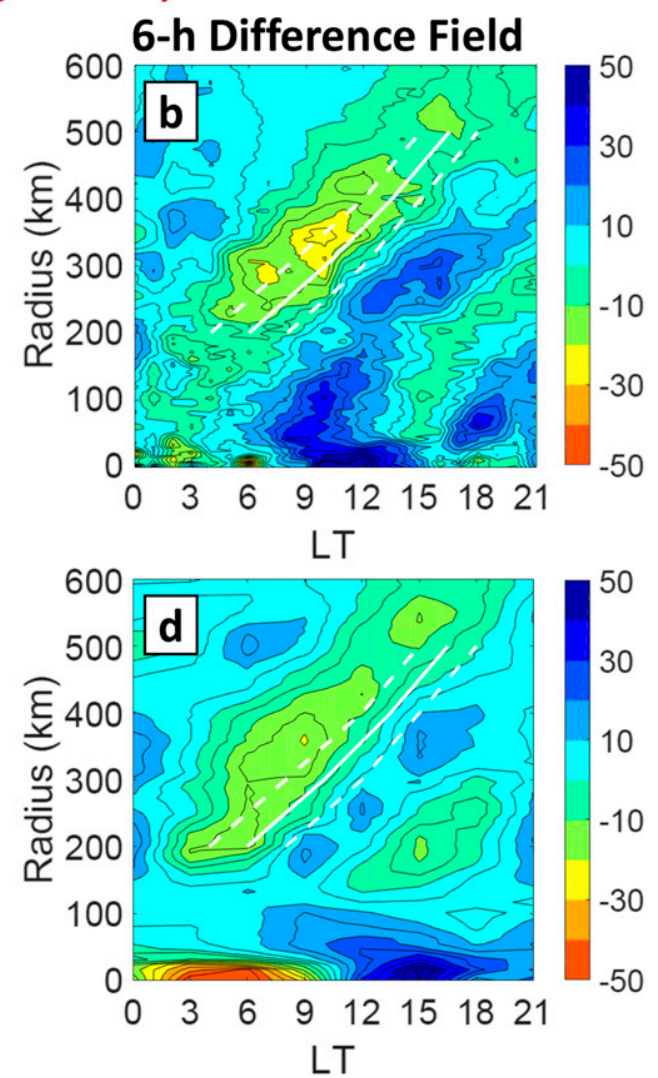

FIG. 4. Azimuthally averaged (a),(c) IR brightness temperatures $\left({ }^{\circ} \mathrm{C}\right)$ and (b),(d) 6-h IR brightness temperature differences $\left({ }^{\circ} \mathrm{C}\right)$ for 0600 UTC (0000 LT) 26 Aug-0300 UTC (2100 LT) 27 Aug from (a),(b) the HRRR and from (c),(d) the observations. White lines correspond to the mean (solid), earliest (leftmost dashed), and latest (rightmost dashed) times of the onset of the diurnal pulse according to the original diurnal clock in Dunion et al. (2014). Note that the colorbars in (b),(d) resemble the conventional IR brightness temperature scale seen in (a),(c), where warmer colors represent colder cloud tops and cooler colors represent warmer cloud tops.

around the 100-km radius (Fig. 5a). By 0600 LT, the pulse had enhanced total condensate at lower levels as well and began to propagate outward through 1800 LT (Figs. 5b,d). Radially inward of the ACT cooling pulse were lower values of total condensate, associated with the trailing warming that followed the ACT cooling pulse.

The ACT cooling pulse was also associated with anomalously cool temperatures that propagated outward at low levels between 900 and $1000 \mathrm{hPa}$ from 0600 to $1200 \mathrm{LT}$ (Figs. 5f,g). This positioning implies that the ACT cooling pulse produced a cold pool in its wake, a feature often associated with tropical squall lines, consistent with the results of Dunion et al. (2019).

Additionally, from 0600 to 1200 LT between 800 and $1000 \mathrm{hPa}$, anomalous radial inflow converged with anomalous radial outflow near the axis of the ACT cooling pulse (Figs. $5 \mathrm{j}, \mathrm{k}$ ). Above the anomalous radial inflow, there was anomalous radial outflow, indicative of an overturning circulation. Also present was a divergence signature between 400 and $600 \mathrm{hPa}$ at $1200 \mathrm{LT}$, suggesting that this was the level of convective outflow. Additionally, in the outflow layer $(100-300 \mathrm{hPa})$, there was enhanced radial outflow at the times of the strongest pulse signature.

Finally, the ACT cooling pulse was associated with an area of anomalous cyclonic flow, indicative of a lowlevel jet. Between 0600 and 1200 LT, the anomalous cyclonic flow was maximized at low levels (Figs. 5n,o). At 1200 LT, it was also maximized at upper levels (Fig. 5o). By 1800 LT, the low-level signature was gone, perhaps because the pulse itself was of weaker amplitude (Fig. 4b). 


\section{ACT Cooling Pulse}

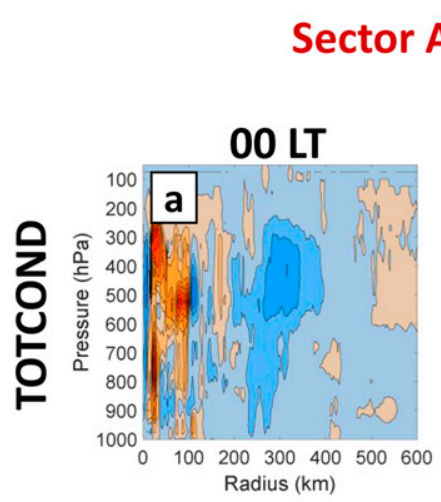

\section{Sector Azimuthally-Averaged Cross-Section Anomalies (26 August 2017)}
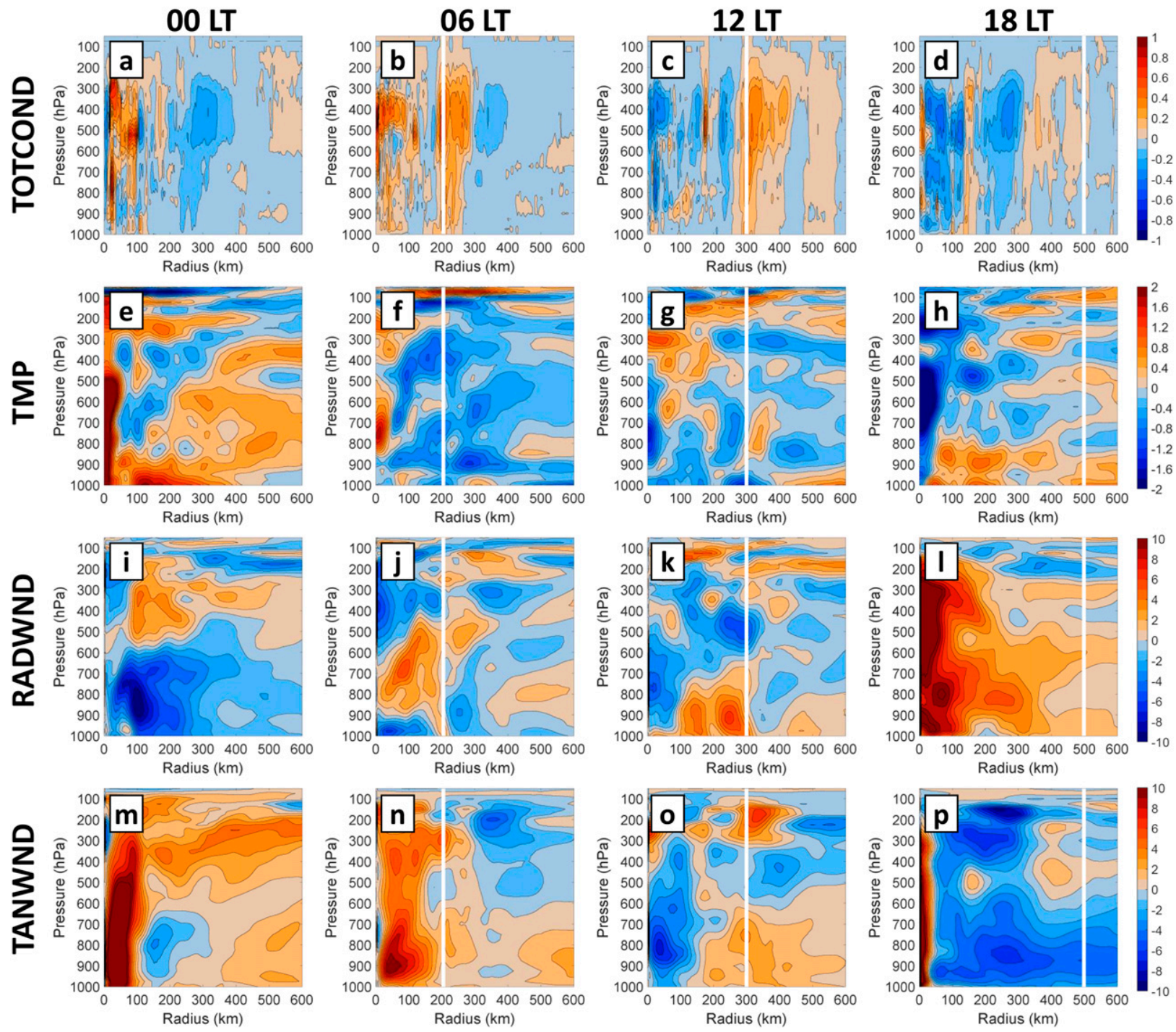

FIG. 5. Anomalies from daily mean, sector-averaged cross sections of (a)-(d) total condensate (TOTCOND; $\left.\mathrm{g} \mathrm{kg}^{-1}\right)$, (e)-(h) temperature (TMP; K), (i)-(l) radial wind (RADWND; $\mathrm{m} \mathrm{s}^{-1}$ ), and (m)-(p) tangential wind (TANWND; $\mathrm{m} \mathrm{s}^{-1}$ ) for the ACT cooling pulse at 0000,0600 , 1200 , and 1800 LT. White vertical lines indicate the radius around which the pulse should occur using the extended version of the Dunion et al. (2014) diurnal clock (Ditchek et al. 2019a, Fig. 2b). Variables are from the analyses of the HRRR model runs for the ACT cooling pulse day.

Overall, the HRRR depicted the ACT cooling pulse as being a column-deep feature with an associated cold pool, converging flow at low levels with an overturning circulation, and enhanced cyclonic flow near the surface and aloft (Fig. 5). These features are reminiscent of the structure of tropical squall lines and tropical cyclone rainbands (e.g., Barnes et al. 1983; Powell 1990a,b; Hence and Houze 2008; Houze 2010; Didlake and Houze 2009; Dunion et al. 2019). Corroborating this rainband-like structure, Fig. 3 shows that the ACT pulse was associated with a rainband-like reflectivity feature that propagated outward over the course of the day beginning around the $100-200-\mathrm{km}$ radius.

\section{ACT warming pulse}

The ACT warming pulse occurred over the 24-h period beginning at 0600 UTC (0000 LT) 28 August. On this day, 


\section{ACT Warming Pulse \\ GridSat-B1 6-h IR Brightness Temperature Differences \\ (28 August 2017)}
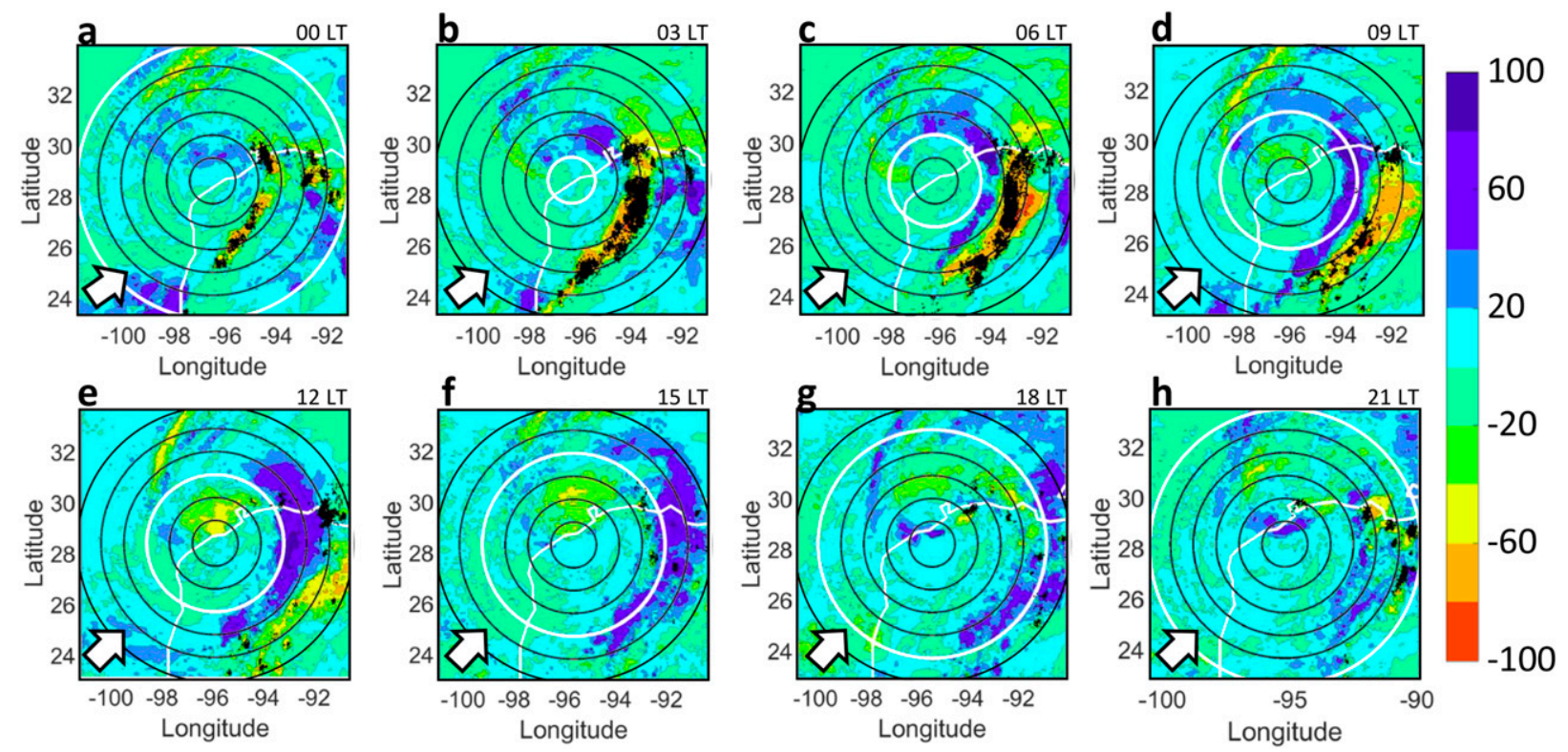

FIG. 6. As in Fig. 1, but for 6-h IR brightness temperature difference fields $\left({ }^{\circ} \mathrm{C}\right)$ on the ACT warming pulse day.

the shear was mostly southwesterly at $15.25 \mathrm{~m} \mathrm{~s}^{-1}$ on average, falling into the high-shear grouping, where high shear $\left(>10.6 \mathrm{~m} \mathrm{~s}^{-1}\right)$ was defined as the upper quartile of the climatological distribution of shear values from Ditchek et al. (2019a).

\section{a. Observations}

The 6-h IR brightness temperature difference evolution with overlaid lightning for the ACT warming pulse every $3 \mathrm{~h}$ from 0000 to $2100 \mathrm{LT}$ is given in Fig. 6. The ACT warming pulse can be seen following the Dunion et al. (2014) clock (white circles; Fig. 6). The lightning, however, was actually part of an off-the-clock ACT cooling pulse that propagated outward ahead of the warming pulse. This off-the-clock ACT cooling pulse preceding a warming pulse was also found in Figs. $7 \mathrm{e}$ and $7 \mathrm{~g}$ of Ditchek et al. (2019b).

Both the warming pulse and the off-the-clock ACT cooling pulse propagated outward on the right-of-shear side of the storm, the dominant side for lightning activity outside of the inner core and the side often associated with ACT pulses (Ditchek et al. 2019b). Hereafter, discussion will mainly focus on this off-the-clock ACT cooling pulse.

As with the ACT cooling pulse that occurred two days prior, the abundant lightning present in the offthe-clock ACT cooling pulse implies that it was a column-deep feature. Therefore, it is not surprising that the corresponding $85-91-\mathrm{GHz}$ microwave imagery evolution depicted that the off-the-clock ACT cooling pulse was comprised of elevated cloud ice content, while the warming pulse was absent of cloud ice (Fig. 7). It is also not surprising that reflectivity was elevated within the off-the-clock ACT cooling pulse and that the warming pulse itself had lower values of reflectivity (Fig. 8).

\section{b. Reproducibility of the observed ACT warming pulse}

The analyses of the 0600 UTC (0000 LT) 28 August0300 UTC (2100 LT) 29 August initializations of the HRRR were used to determine whether the warming pulse and associated off-the-clock ACT cooling pulse were reproduced by the model. The plan-view evolution of the 6-h simulated IR brightness temperature differences showed both the warming pulse as well as the offthe-clock ACT cooling pulse, as found in observations (not shown). Additionally, the azimuthally averaged, simulated, IR brightness temperatures and corresponding 6-h simulated, IR brightness temperature differences (Figs. 9a,b) depicted an off-the-clock ACT cooling pulse, trailed by an on-the-clock warming pulse, that had a similar timing and propagation speed as the observations (Figs. 9c,d). The structures of the warming pulses, 


\section{ACT Warming Pulse}

\section{5-91 GHz Microwave Imagery}

(28 August 2017)
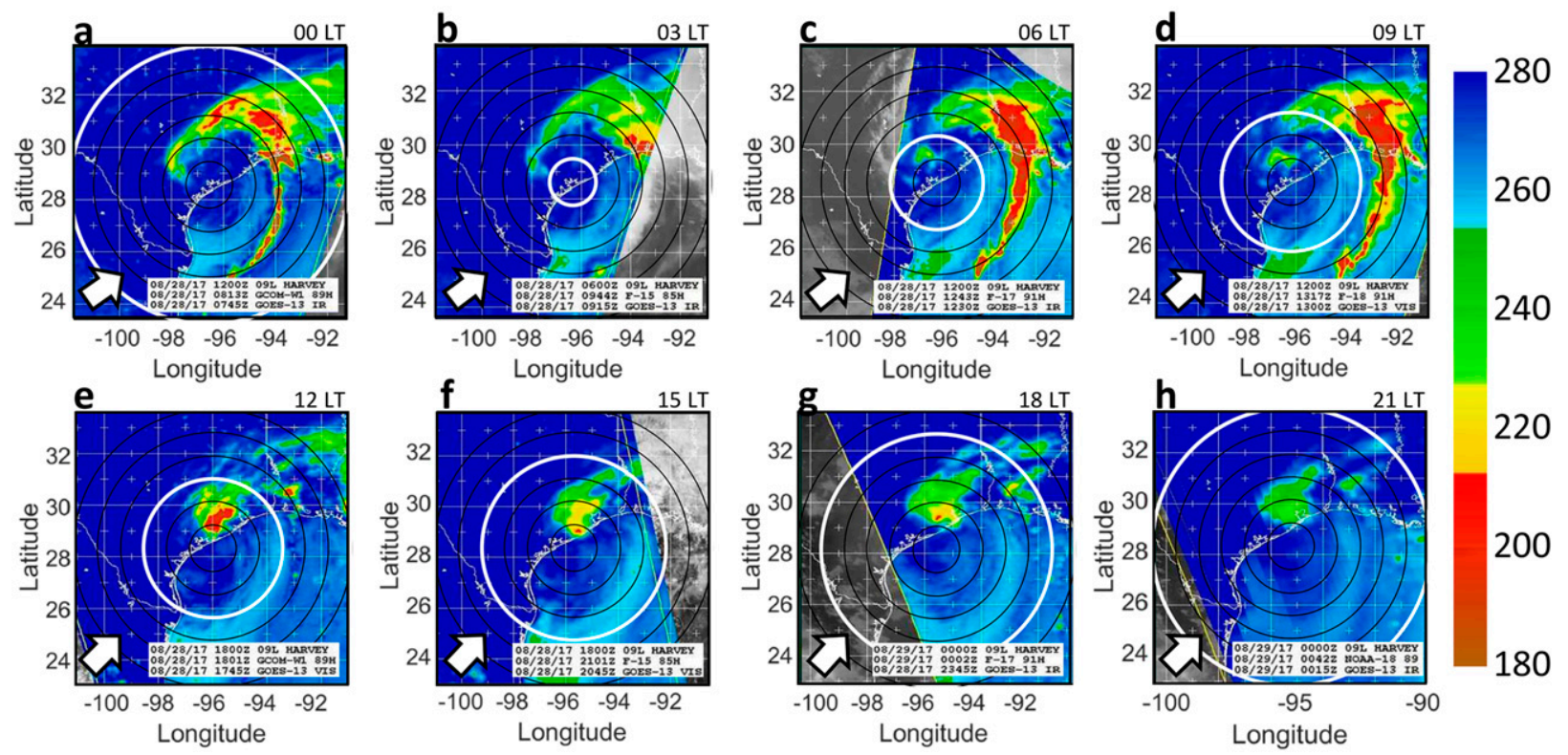

FIG. 7. As in Fig. 1, but for 85-91-GHz microwave imagery (K) without overlaid lightning on the ACT warming pulse day.

\section{ACT Warming Pulse \\ KHGX Reflectivity \\ (28 August 2017)}
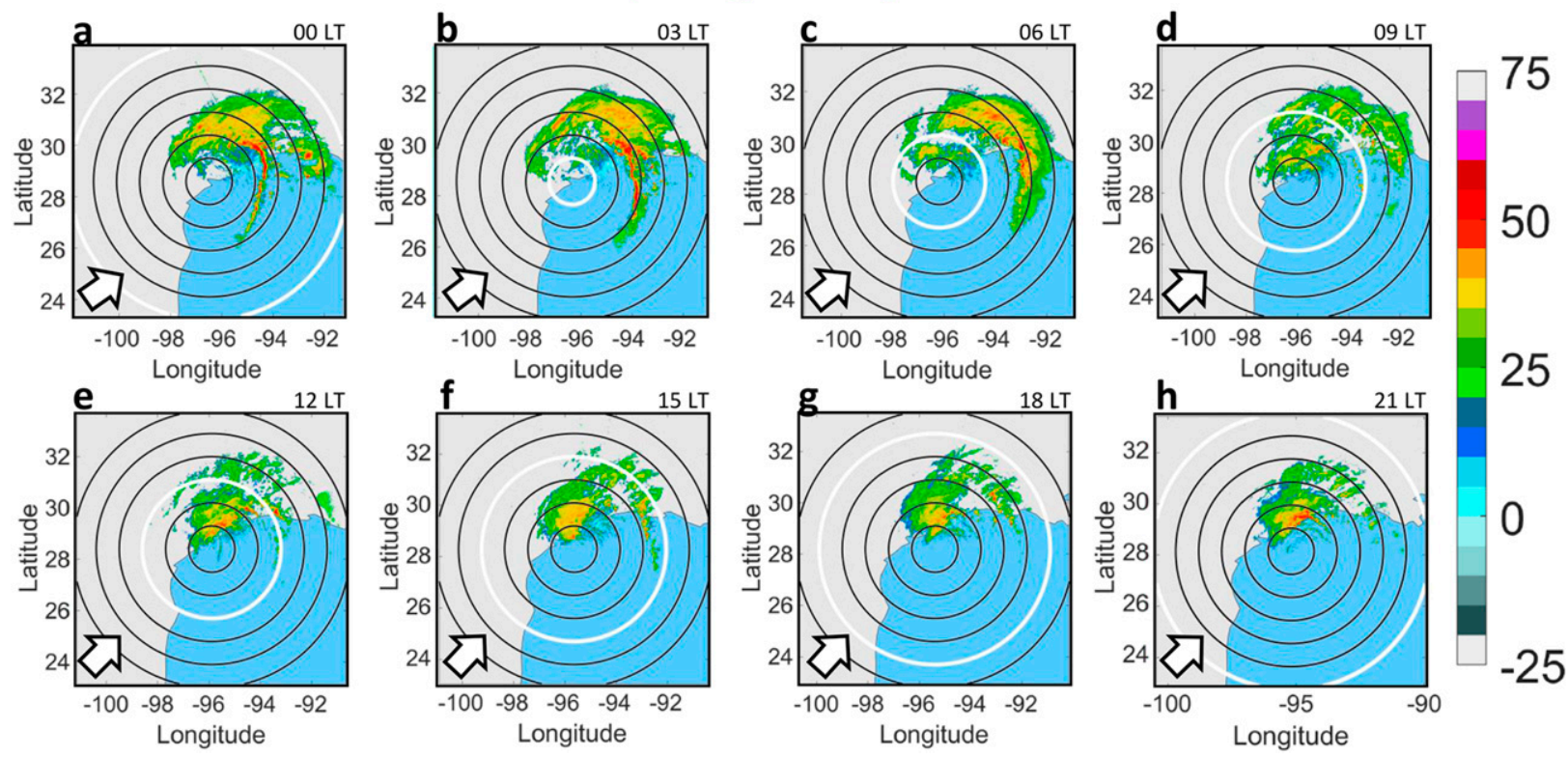

FIG. 8. As in Fig. 1, but for reflectivity (dBZ) without overlaid lightning on the ACT warming pulse day. 


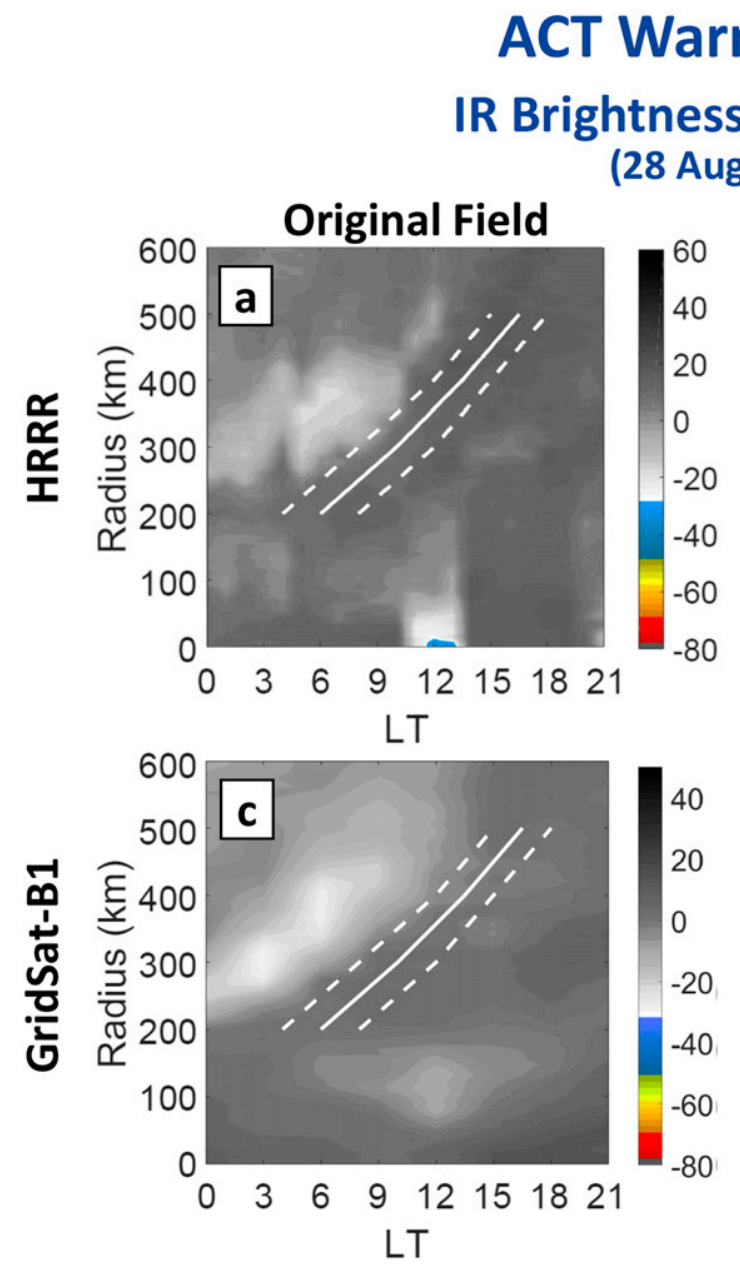

\section{ACT Warming Pulse}

thess Temperatures

August 2017)
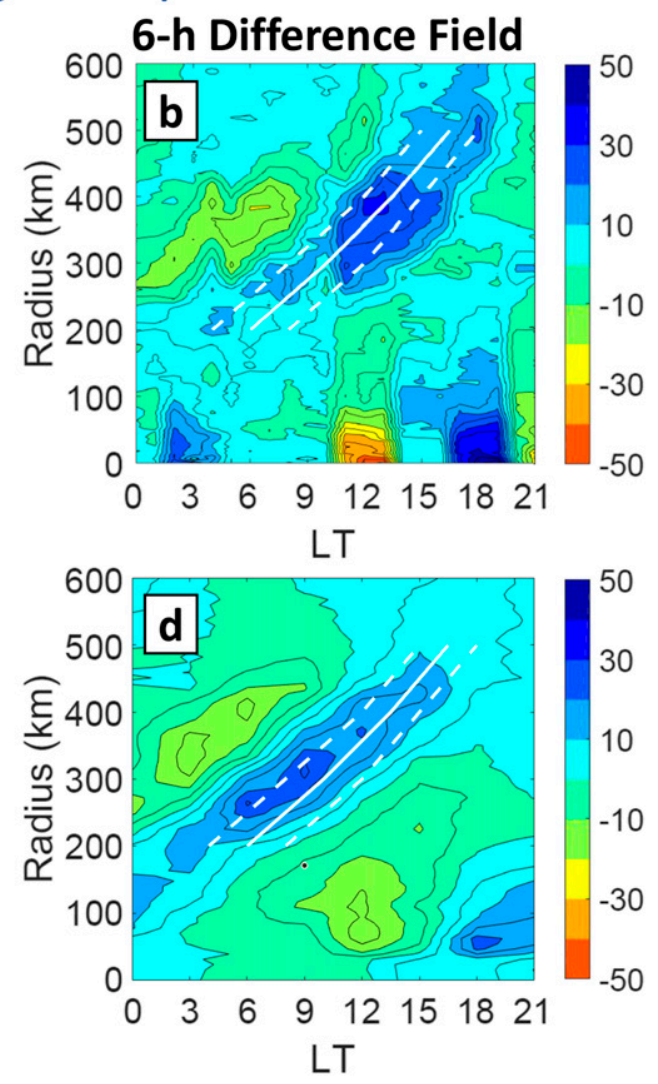

FIG. 9. As in Fig. 4, but for 0600 UTC (0000 LT) 28 Aug-0300 UTC (2100 LT) 29 Aug from (a),(b) the HRRR and from (c),(d) the observations.

however, were slightly different: the observed warming pulse peaked in magnitude around $0800 \mathrm{LT}$ while the HRRR warming pulse peaked in magnitude around 1200 LT. This difference implies that the observed warming pulse was a more coherent feature earlier in the day at a smaller radius than the HRRR warming pulse. Despite these structural differences, the spatial representation and propagation speed similarities between the HRRR and the observations indicate that the HRRR was able to reproduce key aspects of the ACT warming pulse.

\section{c. Thermodynamic and kinematic properties from the HRRR}

As with the ACT cooling pulse, in order to depict the anomalous thermodynamic and kinematic properties associated with the off-the-clock ACT cooling pulse, anomalies from daily mean, sector-averaged cross sections were taken for total condensate, temperature, radial wind, and tangential wind (Fig. 10). ${ }^{5}$ Azimuthal averages were again conducted over the eastern half of Harvey, as that was where the off-the-clock ACT cooling pulse was mainly located (Fig. 6). For reference, a diagram of this sector is included in Fig. 10. Again, for brevity, sectoraveraged cross sections are shown every $6 \mathrm{~h}$, instead of $3 \mathrm{~h}$.

The off-the-clock ACT cooling pulse (white dashed vertical lines) was associated with outward propagating, enhanced total condensate. At 0000 LT, enhanced total condensate values were most prominent at upper and midlevels (Fig. 10a). By 0600 LT, the off-the-clock ACT cooling pulse also had a more cohesive low-level total condensate component (Fig. 10b). At 1200 LT, the off-theclock ACT cooling pulse continued propagating outward (Fig. 10c) and by 1800 LT was beyond the $600-\mathrm{km}$ radius

\footnotetext{
${ }^{5}$ Qualitatively similar results were again found when taking 6-h differences instead of anomalies from the daily mean.
} 


\section{ACT Warming Pulse}
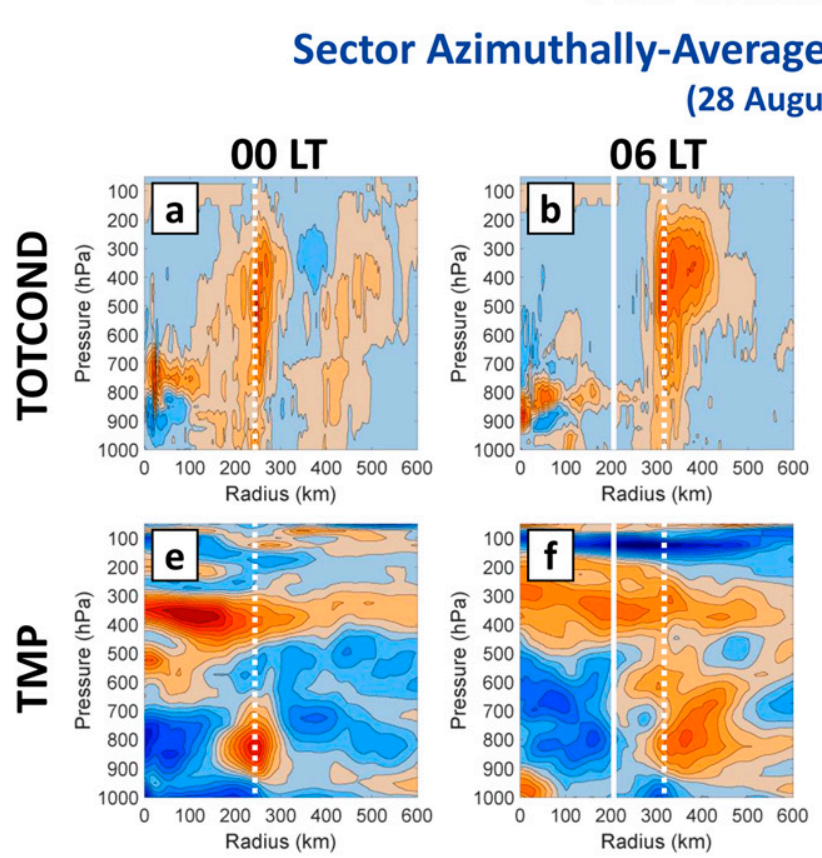

(28 August 2017)
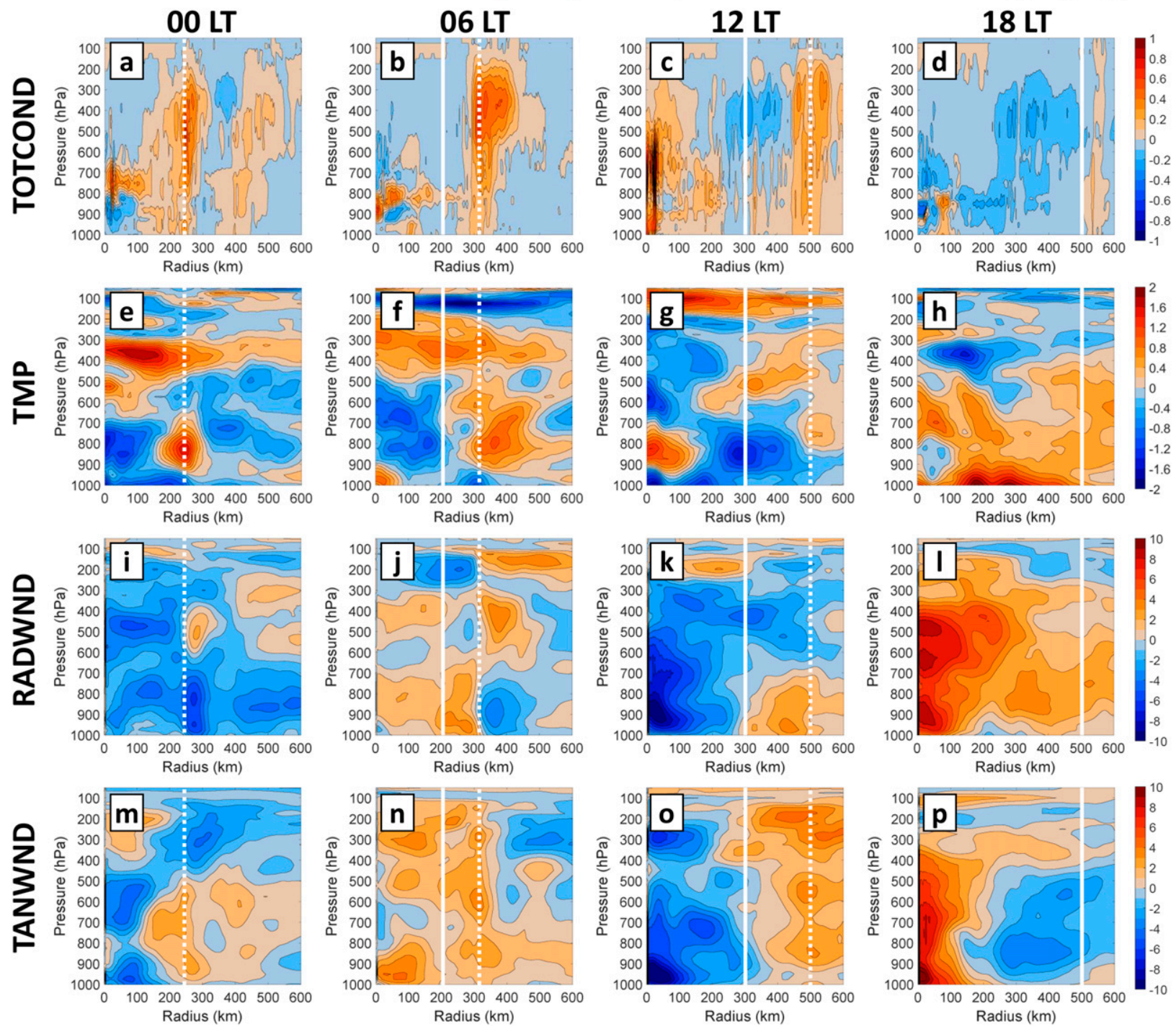

FIG. 10. As in Fig. 5, but for the ACT warming pulse day at 0000, 0600, 1200, and 1800 LT. The additional dashed white vertical lines indicate the radius around which the off-the-clock ACT pulse occurred.

so it does not appear in Fig. 10d. The ACT warming pulse itself was associated with locally lower total condensate values and propagated outward over the course of the day.

As with the ACT cooling pulse, the off-the-clock ACT cooling pulse was associated with anomalous cool temperatures that propagated outward at low levels between 900 and $1000 \mathrm{hPa}$ from 0000 to $1200 \mathrm{LT}$, implying that the off-the-clock ACT cooling pulse produced a cold pool in its wake, consistent with the results of Dunion et al. (2019) (Figs. 10e-g).
The off-the-clock ACT cooling pulse was associated with anomalous radial inflow that converged with anomalous radial outflow between 700 and $1000 \mathrm{hPa}$ with divergence aloft between 400 and $600 \mathrm{hPa}$ at $0000 \mathrm{LT}$ (Fig. 10i). This pattern continued through 1200 LT (Figs. 10j,k) and implies that the off-the-clock ACT cooling pulse was associated with an overturning circulation. Additionally, at 0600 LT between 700 and $1000 \mathrm{hPa}$ at the axis of the warming pulse (solid white line), anomalous radial outflow was located radially outward of weaker anomalous radial inflow - a divergence signature 


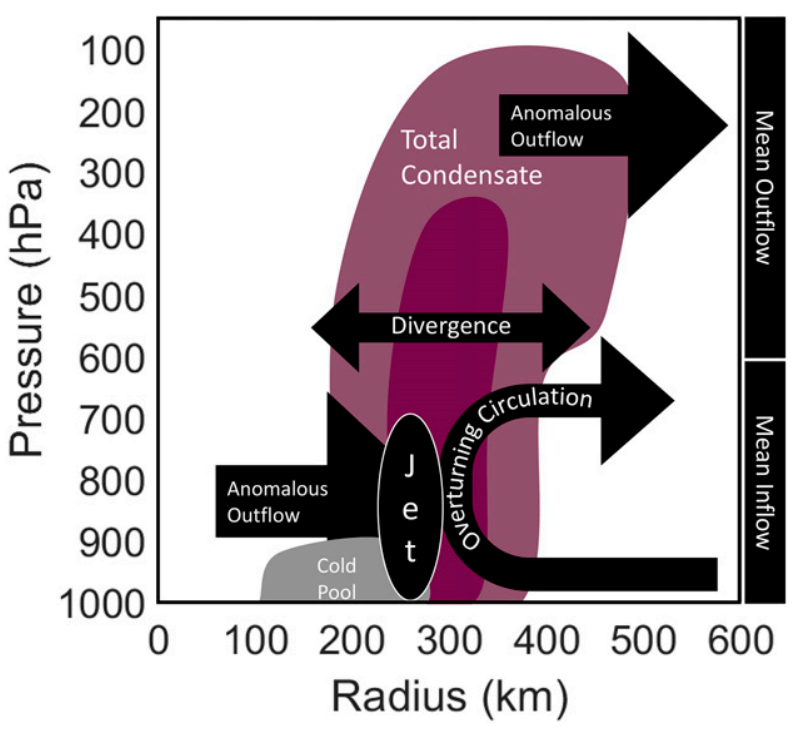

FIG. 11. A cross-sectional schematic of ACT pulse structure based on Figs. 5 and 10. The right side of the graphic depicts the range of levels over which the daily mean radial outflow and inflow occur.

probably due to subsidence associated with the warming pulse (Fig. 10j). This divergence signature was also found at $1200 \mathrm{LT}$ and at $1800 \mathrm{LT}$ near the warming pulse (Figs. 10k,1). Additionally, in the outflow layer (100$300 \mathrm{hPa}$ ), there was enhanced radial outflow at the times of the strongest pulse signature.

Finally, the off-the-clock ACT cooling pulse was associated with an area of outward propagating, anomalous cyclonic flow. At $0000 \mathrm{LT}$, this anomalous cyclonic flow was maximized at low levels (Fig. 10m), indicative of a low-level jet. Between 0600 and 1200 LT, it was maximized at upper levels (Figs. 10n,o). By 1800 LT, the low-level signature was gone, as the off-the-clock ACT cooling pulse was beyond the $600-\mathrm{km}$ radius.

Therefore, the HRRR depicts that the off-the-clock ACT cooling pulse also had characteristics reminiscent of tropical squall lines found in tropical cyclone rainbands. Rainband-like features associated with the off-the-clock ACT cooling pulse were also seen using NEXRAD reflectivity (Fig. 8).

Since both ACT pulses in Harvey had similar structures, a summary schematic is given in Fig. 11. Again, these features are reminiscent of the structure of tropical squall lines and tropical cyclone rainbands found in the literature (e.g., Barnes et al. 1983; Powell 1990a,b; Hence and Houze 2008; Houze 2010; Didlake and Houze 2009; Dunion et al. 2019).

\section{A hypothesis for pulse initiation}

Sections 4 and 5 documented the evolution of two representative ACT diurnal pulses present in Harvey and evaluated whether those pulses behaved like tropical squall lines. This section will investigate the initiation mechanisms of those two pulses.

In the 6-h IR brightness temperature difference evolution of the ACT cooling pulse and the off-theclock ACT cooling pulse, the pulses appeared to begin around the $100-200-\mathrm{km}$ radius. This timing is consistent with the composite results of Ditchek et al. (2019a,b) and the diurnal clock of Dunion et al. (2014); however, whether the pulse actually formed at that radius before propagating outward is unclear. If pulses originated within the $100-200-\mathrm{km}$ radial band, they might not be apparent in the 6-h IR brightness temperature difference evolution since their signatures were too weak to be seen or since a higher spatial and/or temporal resolution is needed to detect them. Therefore, it is important to determine whether there are outward propagating features present in the inner core of Harvey that later become the pulses. One such outward propagating feature might be inner rainbands. While the diurnal pulse is not necessarily a rainband, it is associated with tropical squall-line characteristics (Figs. 5 and 10) and rainband-like features (Figs. 3 and 8).

Numerical modeling and observational studies have been conducted that explore how inner rainbands can become principal and distant rainbands. In an idealized tropical cyclone simulation, $\mathrm{Li}$ and Wang (2012a,b) found that outward propagating inner rainbands were stretched in the rapid filamentation zone (RFZ): the region where deep-convective clouds cannot form or be sustained since the deformation is much larger than the vorticity, corresponding to filamentation times of less than 30-45 min (Rozoff et al. 2006). Once beyond the RFZ, if the environment is favorable for deep convection, the inner-rainband remnants can reinvigorate and form an outer spiral rainband.

Li et al. (2017) expanded on the Li and Wang (2012b) results by introducing vertical wind shear into their numerical model. With the introduction of shear, three different initiation mechanisms for inner rainbands became apparent: 1) convectively coupled vortex Rossby waves (VRWs) propagated radially outward at around $9.5 \mathrm{~m} \mathrm{~s}^{-1}$ in the downshear half of the storm and accumulated at the stagnation radius, often 3 times the radius of maximum wind (RMW) and the outer extent of innercore circulation (e.g., Montgomery and Kallenbach 1997; Reasor et al. 2000; Corbosiero et al. 2006); 2) weak convective cells present in the upshear-right quadrant of the storm were advected and strained downshear (Moon and Nolan 2015b); and, 3) multiple strained convective cells merged downshear (Moon and Nolan 2015b). Regardless of the inner-rainband formation mechanism, if the inner rainbands propagated outward beyond the region dominated inner-core dynamics (around 3 times 
the RMW) into an area favorable for deep convection, they were able to become outer rainbands, thus corroborating the earlier results of $\mathrm{Li}$ and Wang (2012b).

More recently, Yu et al. (2018) used radar analyses to study outer tropical cyclone rainbands as they approached Taiwan between 2003 and 2015 with the goal of quantifying how often squall-line structures were present. They found that around $60 \%$ of their sample had squall-line-like airflow patterns (i.e., were associated with converging airflow at low levels and cold pools). These patterns were also found by Yu and Tsai (2013). From their analysis, Yu et al. (2018) speculated that rainbands propagated from the inner, wave-dominant region to the outer region of a tropical cyclone where squall-line dynamics took over. Thus, their results did not conflict with the wave-dynamics interpretation of tropical cycle inner rainbands.

The literature has, therefore, provided evidence on how outer rainbands can be formed from inner rainbands. Since the diurnal pulses in Harvey were found to be associated with tropical squall-line characteristics (Figs. 5 and 10) and rainband-like features (Figs. 3 and 8), the hypothesis for diurnal pulse initiation is, therefore, similar to the mechanism for inner-to-outer rainband transformation: inner rainbands that propagate outward into a more favorable environment for deep convection take on tropical squall-line characteristics. The enhanced convection then becomes visible in the 6-h IR brightness temperature differences as a diurnal pulse and propagation is furthered by a low-level cold pool. Innerrainband occurrence is not diurnal, however (e.g., Corbosiero et al. 2006; Moon and Nolan 2015a,b). Therefore, the timing of their outward propagation must be key to diurnal-pulse formation. Since the literature has found that there is an overnight and early morning peak of inner-core deep convection, lightning, and tropical cyclone rainfall (Ditchek et al. 2019a, Fig. 1), it is speculated that inner rainbands that propagate outward overnight and in the early morning would enter an environment that is more favorable for deep convection and, therefore, become the diurnal pulses seen in the 6-h IR brightness temperature differences.

It is important to note that the aim of this section is not to determine the formation mechanisms of inner and outer rainbands, or to claim that diurnal pulses are rainbands. Rather, it is to understand whether inner rainbands were the preceding structure to the diurnal pulses in Harvey.

\section{a. Data and methods}

To determine whether the ACT cooling and off-theclock ACT cooling pulses formed from inner rainbands, a data source with high temporal and spatial resolution is needed. Since the NEXRAD reflectivity data has an approximately 5-min temporal resolution, NOAA's Weather and Climate Toolkit was again used, but at 30-min intervals from: 1) KCRP beginning at $1800 \mathrm{LT}$ the day before through $0600 \mathrm{LT}$ the day of the ACT cooling pulse, and 2) KHGX beginning at $1200 \mathrm{LT}$ the day before through 0000 LT the day of the ACT warming pulse. The reason for this 6 -h time difference was so that the origin of the off-the-clock ACT cooling pulse could be determined. To generate storm-centered grids of the radar data, the HURDAT2 data described in section 2 were linearly interpolated to a temporal resolution of $30 \mathrm{~min}$.

While the location of the RFZ could not be determined from observations, the location of the stagnation radius (around 3 times the RMW) was estimated using four times daily operational estimates of the RMW for the ACT cooling and off-the-clock ACT cooling pulse days from the "extended best track" dataset (EBT; Demuth et al. 2006) that were linearly interpolated to a temporal resolution of $30 \mathrm{~min}$.

\section{b. Results}

\section{1) ACT COOLING PULSE}

Figure 12 depicts the evolution of the KCRP reflectivity data every $30 \mathrm{~min}$ beginning at $1800 \mathrm{LT}$ the day before through 0600 LT the day of the ACT cooling pulse. Between 1800 and 1830 LT the day before the ACT cooling pulse occurred, an inner rainband (yellow shading) propagated away from the eyewall on the western side of the storm (purple arrow). This rainband then propagated cyclonically around the storm, was filamented by the flow, and was located at the estimated stagnation radius (red circle) on the eastern side of the storm by 1900-2000 LT. From 2030 to 2230 LT, the RMW and, therefore, stagnation radius, contracted slightly, and so the remnants of the filamented inner rainband became located outside of the stagnation radius. Shortly thereafter, convection reinvigorated around $150 \mathrm{~km}$ and remained stationary between 0000 and 0330 LT. By 0400 LT, the rainband began propagating outward so that by $0600 \mathrm{LT}$ it was located around the $200-300-\mathrm{km}$ radius. This rainband is the ACT cooling pulse seen in Figs. 1-3.

By examining the sector-averaged, radius-time evolution of the reflectivity data depicted in Fig. 12 (not shown), it was found that the outward-propagating inner rainband had a slower propagation speed than the ACT cooling pulse: $6.2 \mathrm{~m} \mathrm{~s}^{-1}$ between 75 and $125 \mathrm{~km}$ and $4.4 \mathrm{~m} \mathrm{~s}^{-1}$ between 125 and $200 \mathrm{~km}$. These speeds are consistent with VRW theory (e.g., Montgomery and Kallenbach 1997; Corbosiero et al. 2006) and, therefore, the presence of the inner rainband is consistant with 


\section{ACT Cooling Pulse}

\section{KCRP Reflectivity}

(18 LT 25 August 2017 - 06 LT 26 August 2017)

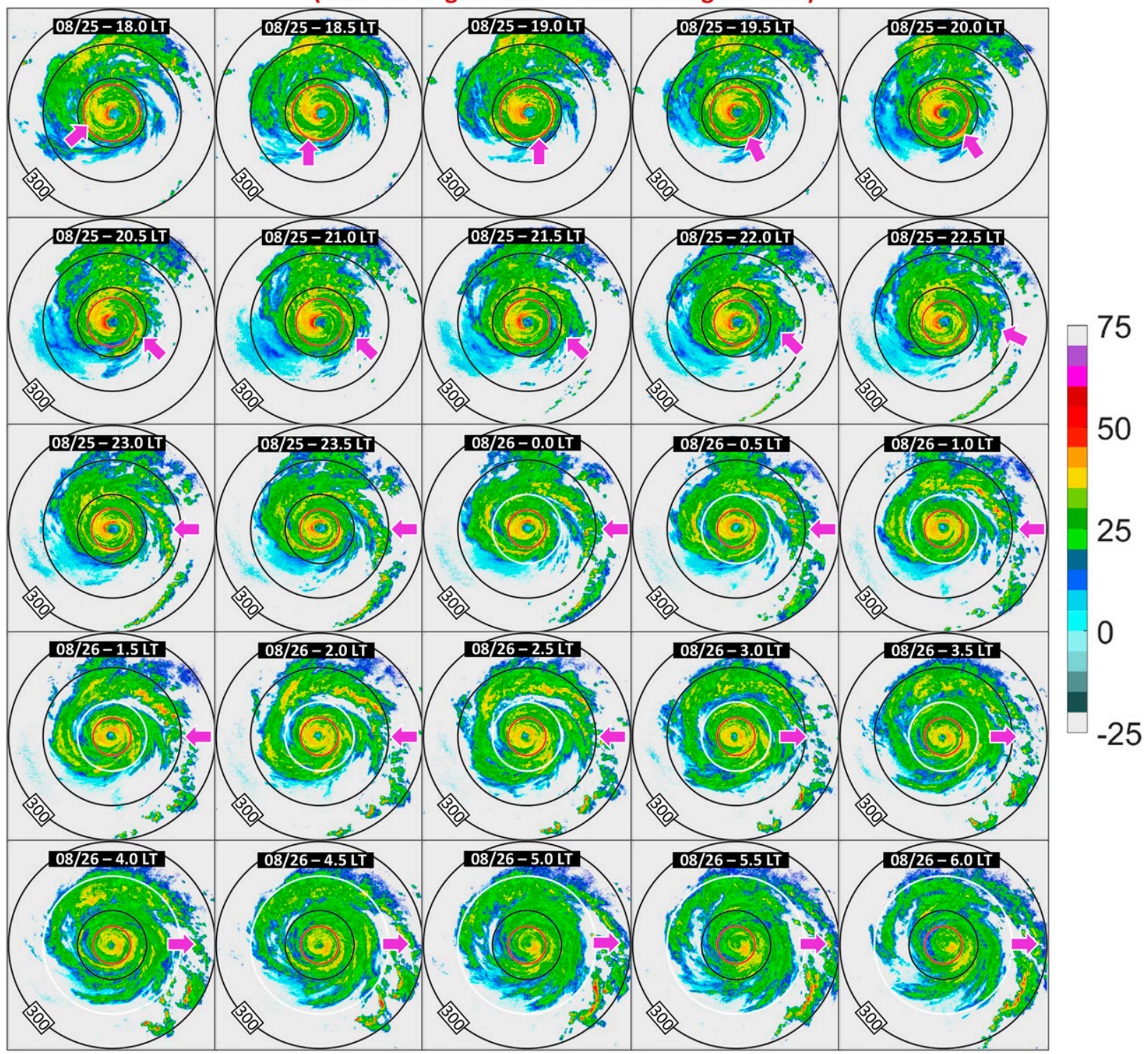

FIG. 12. A plan view of storm-centered KCRP NEXRAD reflectivity data (dBZ) every 30 min from 1800 LT the day before through $0600 \mathrm{LT}$ the day of the ACT cooling pulse. Black range rings are overlaid on each image every $100 \mathrm{~km}$ from $r=100-300 \mathrm{~km}$. White range rings indicate the radius at which the pulse should occur using the extended version of the Dunion et al. (2014) diurnal clock (Ditchek et al. 2019a, Fig. 2b). The red range ring indicates 3 times the RMW, the approximate location of the stagnation radius for VRWs. The purple arrows track the evolution of the ACT cooling pulse. Coastlines were removed from these graphics for aesthetic reasons.

the first inner-rainband initiation mechanism detailed by Li et al. (2017).

To determine whether the environment into which the inner rainband moved was favorable for deep convection, CAPE from the HRRR was retrieved the day prior to the ACT cooling pulse. Three representative times are given in Fig. 13 and are overlaid with the associated reflectivity fields from Fig. 12. The three times chosen include: 1) 1930 LT — when the inner rainband was stalled at the stagnation radius, 2) 2130 LT-after the inner rainband moved beyond the stagnation radius, and 3) 2330 LT-when convection reinvigorated. At all times, CAPE was found to be elevated in the Gulf of Mexico, just outside of the $100-\mathrm{km}$ radius. 


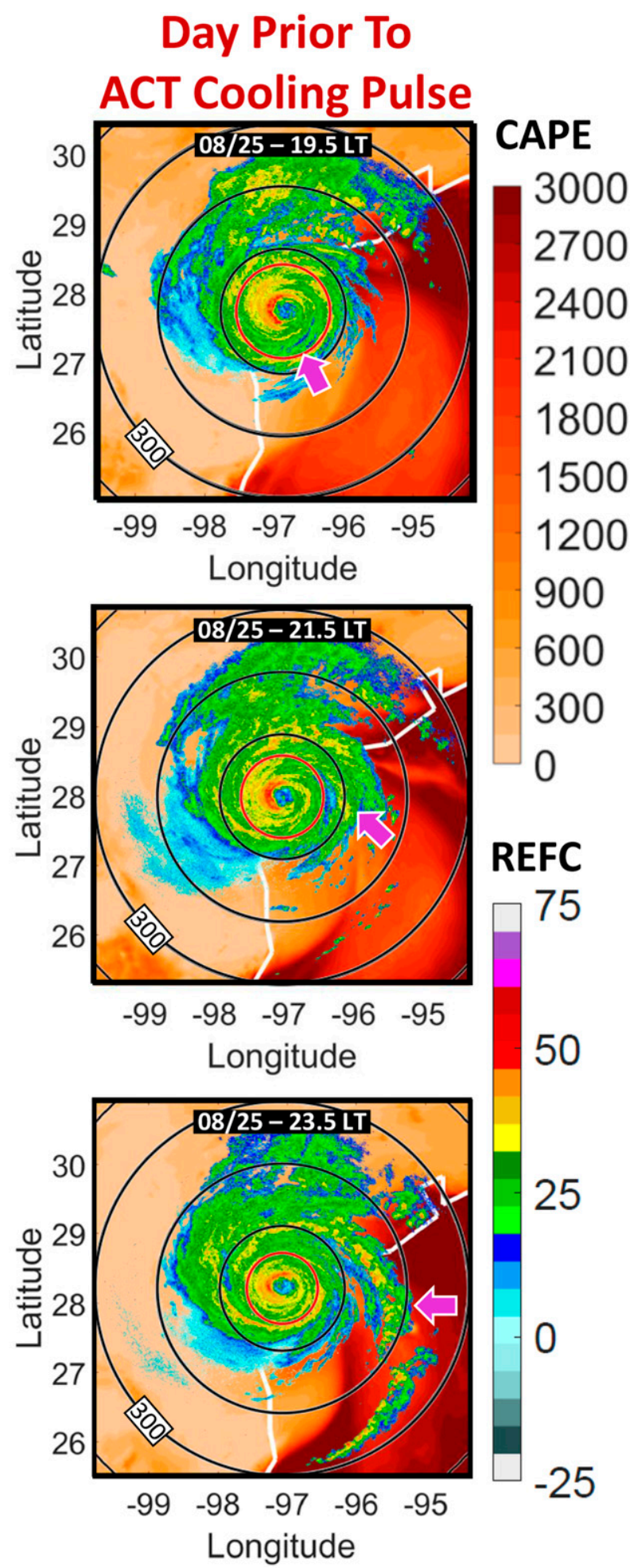

FIG. 13. A plan view of CAPE from the HRRR overlaid with NEXRAD reflectivity (dBZ) from Fig. 12 for 1930 LT, 2130 LT, and 2330 LT the day prior to the ACT cooling pulse. As in Fig. 12, black range rings are overlaid on each image every $100 \mathrm{~km}$ from $r=$ $100-300 \mathrm{~km}$, the red range ring indicates 3 times the RMW, the approximate location of the stagnation radius for VRWs, and the purple arrows tracks the evolution of the pulses.
As the inner rainband moved beyond the stagnation radius on the eastern side of Harvey, it moved into a region more favorable for deep convection. By $2330 \mathrm{LT}$, the inner rainband had already reinvigorated and CAPE was found to be decreased in that region.

The hypothesis for ACT pulse initiation is, therefore, supported.

\section{2) ACT WARMING PULSE}

The off-the-clock ACT cooling pulse was found to propagate outward around $6 \mathrm{~h}$ earlier than an on-theclock pulse. Therefore, Fig. 14 depicts the evolution of the KHGX reflectivity data every $30 \mathrm{~min}$ beginning at 1200 LT the day before through 0000 LT the day of the off-the-clock ACT cooling pulse. The RMW was located around $140 \mathrm{~km}$ and, therefore, the estimated stagnation radius (around $420 \mathrm{~km}$ ) is not visible in Fig. 14.

The evolution of the off-the-clock ACT cooling pulse was different than that of the ACT cooling pulse. Between 1200 and 1900 LT the day prior to the off-theclock ACT cooling pulse, multiple, discrete reflectivity features propagated outward, collecting just outside of the RMW at the $160-\mathrm{km}$ radius. The high-reflectivity feature then began to intensify and convection invigorated both upwind and downwind between 1930 and 2130 LT. Between 2200 and 0000 LT, the line of convection began to propagate outward as the off-the-clock ACT cooling pulse. Since the RMW was around the $140-\mathrm{km}$ radius, it is possible that convective features that formed near the RMW were strained by the flow and merged downshear to create a larger, well-organized rainband. This mechanism is similar to the third innerrainband initiation mechanism detailed by Li et al. (2017). While not outside the stagnation radius, it will be shown that the rainband moved into an area favorable for deep convection.

CAPE from the HRRR was retrieved the day prior to the off-the-clock ACT cooling pulse. Figure 15 depicts three representative times overlaid with the associated reflectivity fields from Fig. 14. The three times chosen include: 1) 1930 LT-after the inner rainband formed, 2) $2130 \mathrm{LT}$-after convection began to reinvigorate, and 3) $2330 \mathrm{LT}$-while the offthe-clock ACT cooling pulse began to propagate outward. As with the ACT cooling pulse, the environment into which the eastward propagating diurnal pulse moved was favorable for deep convection. The trailing warming pulse, on the other hand, was associated with a lack of CAPE, probably due to the depletion of CAPE by the off-the-clock ACT cooling pulse. Additionally, CAPE across the Gulf of Mexico was higher the day prior to the off-the-clock ACT 


\section{ACT Warming Pulse}

\section{KHGX Reflectivity}

(12 LT 27 August 2017 - 00 LT 28 August 2017)

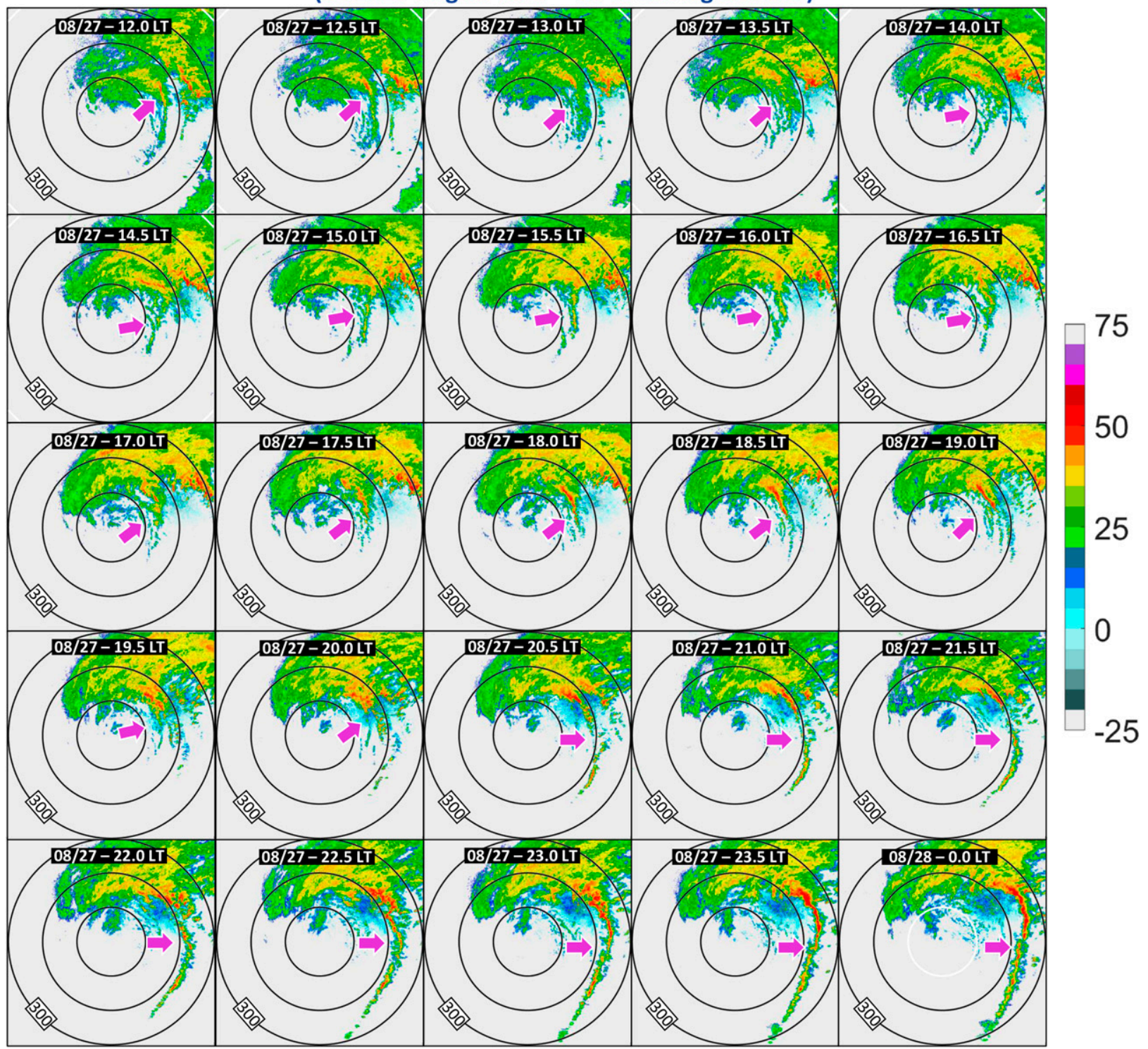

FIG. 14. As in Fig. 12, but for KHGX NEXRAD reflectivity data (dBZ) from 1200 LT the day before through 0000 LT the day of the ACT warming pulse.

cooling pulse than the day prior to the ACT cooling pulse. Perhaps the overall more favorable environment allowed for tropical squall-line dynamics to begin sooner, which would allow for earlier propagation by the low-level cold pool, thus explaining why the ACT cooling pulse that occurred that day was off-theclock. More case studies of off-the-clock ACT cooling pulses should be conducted to identify whether this is the case.
The hypothesis for ACT pulse initiation is, therefore, also supported by this case.

\section{Conclusions}

Ditchek et al. (2019a) generated a climatology of Atlantic basin tropical cyclone cooling and warming pulses over a 36-yr period by creating an objective metric to identify pulses with similar temporal phasing 


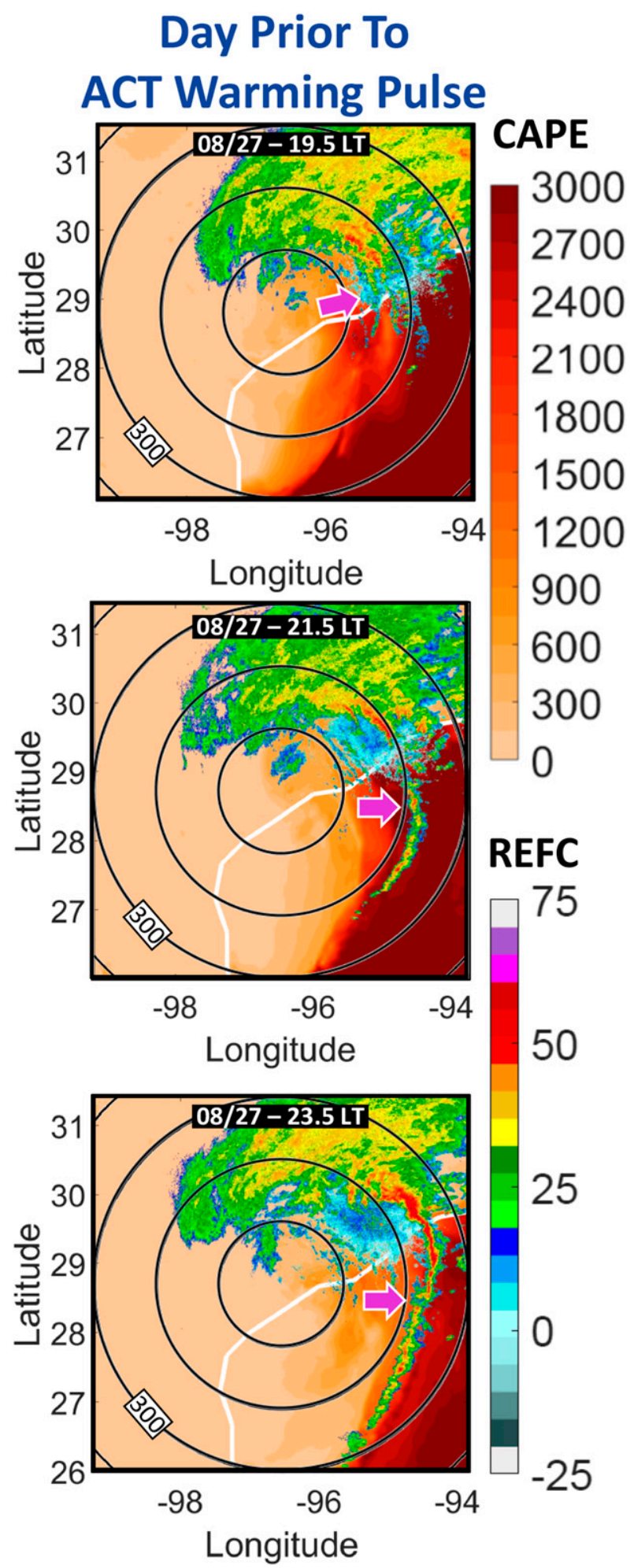

FIG. 15. As in Fig. 13, but with NEXRAD reflectivity (dBZ) from Fig. 14 for the day prior to the ACT warming pulse. as Dunion et al. (2014). By taking 6-h IR brightness temperature differences of GridSat-B1 imagery, they created their metric by using critical thresholds for the magnitude of the IR brightness temperature differences, areal coverage of cold cloud tops, and longevity. Ditchek et al. (2019b) then used WWLLN lightning data from 2005 to 2017 to identify pulses that were electrically active and pulses that were electrically inactive based on an objective metric that incorporated lightning flash density, areal coverage, and longevity within a pulse.

Both Ditchek et al. (2019a,b) were composite studies. To gain further insight into pulse characteristics, here, an ACT cooling pulse and an ACT warming pulse that occurred in Hurricane Harvey (2017) were studied in depth using observations as well as the HRRR analysis fields, as the University of Utah MesoWest HRRR archive only retained forecast hour 0 (i.e., the analysis) for three-dimensional fields. Since the HRRR assimilates available observations, including reflectivity, prior to each initialization, it was expected that the structure and timing of both the ACT cooling pulse and the off-the-clock ACT cooling pulse would be reproduced. Using the HRRR, therefore, allowed for the exploration of fields not readily obtainable from observations.

A notable feature of the ACT warming pulse is that it is associated with an off-the-clock ACT cooling pulse that propagated outward ahead of the warming pulse. Most of the results discussed in this paper, therefore, focused on comparing the ACT cooling pulse to the offthe-clock ACT cooling pulse with three main goals: 1) to document the evolution of the pulses, 2) to evaluate whether the pulses had tropical-squall-line characteristics, and 3) to identify their initiation mechanisms.

The ACT cooling pulse and the off-the-clock ACT cooling pulse were found to share many characteristics:

- Both pulses were identifiable in the 6-h IR brightness temperature differences imagery and propagated outward on the right-of-shear side of Harvey, the dominant side for overall lightning activity outside of the inner core (Figs. 1 and 6).

- Elevated cloud ice content was present in both the ACT cooling pulse and the off-the-clock ACT cooling pulse, as seen in the 85-91-GHz microwave imagery (Figs. 2 and 7), implying that the pulse was column deep.

- Both pulses were also associated with outward propagating rainband-like reflectivity features (Figs. 3 and 8).

- The HRRR was able to reproduce the structure and timing of both the ACT cooling pulse and the off-theclock ACT cooling pulse, allowing for various fields in the HRRR to be examined (Figs. 4 and 9). 
- Using the HRRR, it was found that both the ACT cooling pulse (Fig. 5) and the off-the-clock ACT cooling pulse (Fig. 10) were associated with: 1) elevated total condensate that was column deep; 2) a surface cold pool; 3) an overturning circulation; and, 4) enhanced cyclonic flow at low levels. These characteristics are similar to those found in tropical squall lines.

Since the pulses were found to be associated with tropical squall-line characteristics (Figs. 5 and 10) and rainband-like features (Figs. 3 and 8), a hypothesis was introduced for ACT pulse initiation: ACT pulses originated from inner rainbands that propagated into a more favorable environment for deep convection. At these outer radii, they reinvigorated, taking on tropical squall-line characteristics. Using NEXRAD reflectivity data, it was found that the ACT cooling pulse formed from an inner rainband that propagated outward beginning around 1800 LT the day before the ACT cooling pulse occurred (Fig. 12) and that the offthe-clock ACT cooling pulse formed from multiple convective features that were strained by the flow and merged downshear to create a rainband (Fig. 14). The inner rainbands then moved into a high-CAPE environment, where convection reinvigorated, taking on tropical squall-line characteristics (Figs. 13 and 15). Further propagation was likely aided by the low-level cold pool found in Figs. 5 and 10. Additional case studies of ACT pulses should be conducted to determine how frequently these initiation mechanisms occurred for ACT cooling pulses and off-the-clock ACT cooling pulses.

While this case study provided a comprehensive analysis of an ACT cooling pulse and an off-the-clock ACT cooling pulse associated with an identified ACT warming pulse, there are still many questions that remain unanswered. For example, recent papers have provided a gravity wave interpretation of diurnal pulses (Navarro et al. 2017; O'Neill et al. 2017; Ruppert and O'Neill 2019; Evans and Nolan 2019). The composite results of (Ditchek et al. 2019a) supported this theory, especially their finding that days with enhanced, overnight convection were associated with days that had cooling pulses, as diabatic heating is one source of gravity wave generation. Furthermore, Ditchek et al. (2019b) found that the propagation speed of ACT cooling and warming pulses was consistent with that of gravity waves. Other than the fact that the pulses had similar propagation speeds to gravity waves, this case study, however, could not make any connections between the ACT pulses and gravity waves since the HRRR model analyses did not provide vertical velocity fields.

Furthermore, while it was found that the ACT cooling pulse and off-the-clock ACT cooling pulse in Harvey shared many similar characteristics, this paper could not conclusively answer what caused the off-the-clock ACT cooling pulse to be "off the clock". One hypothesis is that days that have an off-the-clock ACT cooling pulse have environments that are more favorable for deep convection (cf. Figs. 13 and 15). Thus, tropical squall-line dynamics would occur sooner and earlier propagation outward would be aided by a low-level cold pool. Additionally, since Ditchek et al. (2019b) found that ACT warming pulses occurred most often in high shear environments, another hypothesis for the existence of off-the-clock ACT cooling pulses is that the wavenumber-1 asymmetry associated with highly sheared storms could force a pulse to be off-the-clock. If so, then the on-the-clock warming pulse observed would be the trailing warming typically associated with a cooling pulse. In direct contradiction to this hypothesis, however, is the fact that INACT warming pulses were also found to occur in high-shear environments, but were not found to be associated with an offthe-clock ACT or INACT cooling pulse (Ditchek et al. 2019b, Fig. 6).

Additionally, INACT cooling pulses and warming pulses were not discussed in this paper, as INACT pulses in Harvey occurred before Harvey's center was $400 \mathrm{~km}$ from the southern HRRR boundary and after Harvey's final landfall. Since INACT cooling pulses could be associated with nonelectrified convection or could merely be a cirrus canopy feature, and since INACT warming pulses were not associated with convection and had a propagation speed that did not support the gravity wave interpretation of diurnal pulses (Ditchek et al. 2019b), a similar analysis as provided by this paper should be conducted on a storm that had an INACT warming pulse.

Acknowledgments. The authors wish to thank reviewer John Knaff as well as two anonymous reviewers for their insightful comments, which helped to improve the manuscript. GridSat-B1 IR brightness temperature was acquired from NOAA's National Centers for Environmental Information (https://www.ncdc.noaa.gov/ cdr/fundamental/geostationary-ir-channel-brightnesstemperature-gridsat-b1). The authors wish to thank the World Wide Lightning Location Network (http://wwlln.net), a collaboration among over 50 universities and institutions, for providing the lightning location data used in this paper. Additionally, the authors thank the University of Utah MesoWest HRRR archive for providing access to 

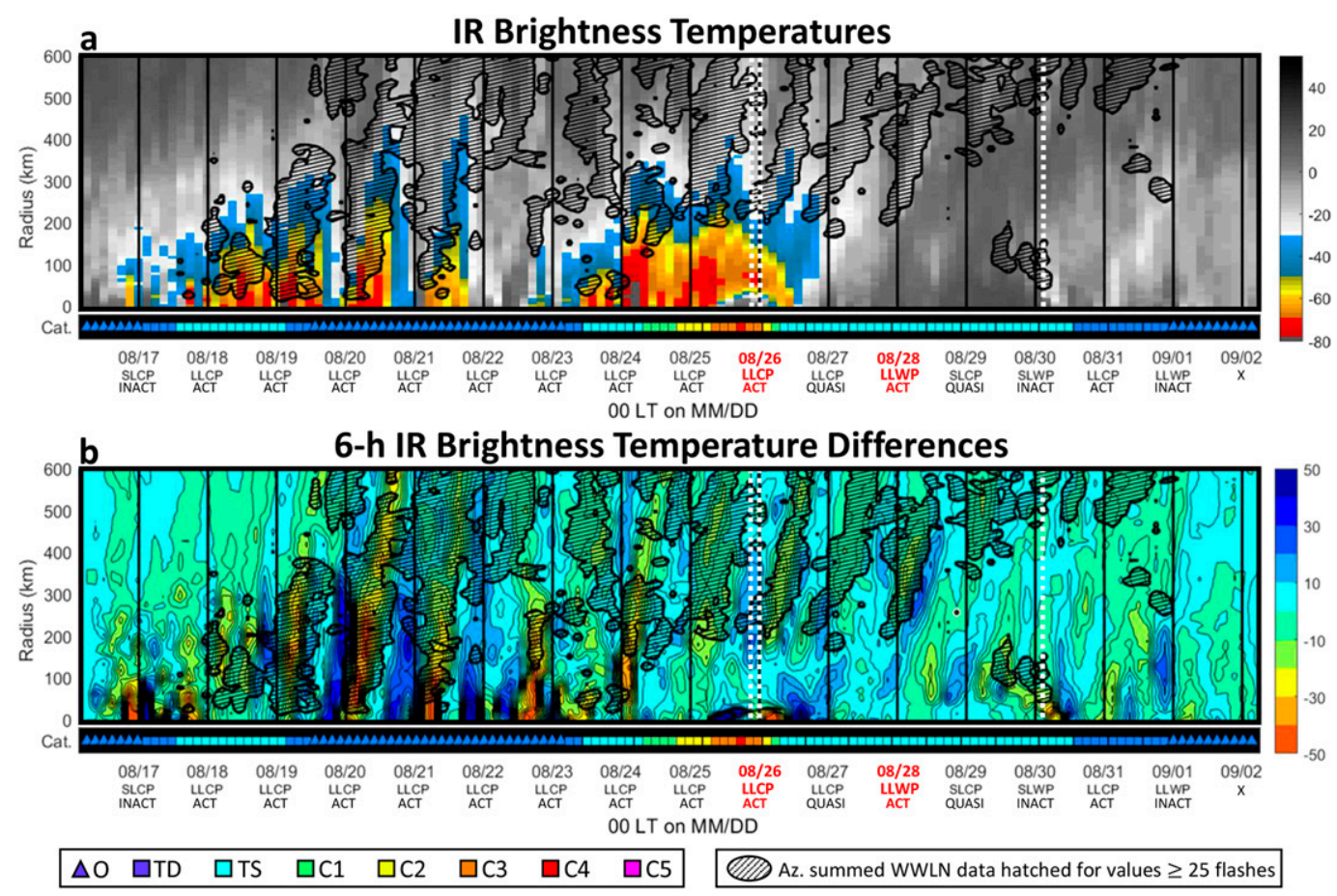

FIG. A1. Azimuthally summed WWLLN lightning flash data (hatched for values $\geq 25$ flashes) overlaid onto azimuthally averaged (a) IR brightness temperatures $\left({ }^{\circ} \mathrm{C}\right.$ ) and (b) 6-h IR brightness temperature differences $\left({ }^{\circ} \mathrm{C}\right)$ over the lifetime of Hurricane Harvey (2017). Black vertical lines correspond to 0000 LT on each day. White dashed lines indicate landfall in the continental United States (Blake and Zelinsky 2017). Red text indicates 0000 LT on the two representative days detailed in this paper. The colored squares represent the intensity of Harvey according to the Saffir-Simpson hurricane wind scale (Simpson 1974) categories: tropical depression (dark blue), tropical storm (cyan), category 1 (green), category 2 (yellow), category 3 (orange), category 4 (red), and category 5 (magenta). The dark blue triangles represent times when the storm was designated as a low, wave, or extratropical by HURDAT2. The pulse type and electric activity classification for each day is listed under the $x$-axis labels and was determined by the objective metrics in Ditchek et al. $(2019 \mathrm{a}, \mathrm{b})$. An " $\times$ " below the $x$-axis labels indicates that the objective metric was not run for that date.

HRRR data (Blaylock et al. 2017). All authors were supported by NSF Grant AGS1636799.

\section{APPENDIX}

\section{Lifetime Diurnal-Pulse Activity in Hurricane Harvey (2017)}

As detailed in section 3, while Harvey occurred over an 18-day period, there were only 16 full (0000-2300 LT) storm days. Each of those days was first given a pulsetype classification using the objective metric from Ditchek et al. (2019a). Cooling and warming pulse days were then classified based on their electric activity using the objective metric from Ditchek et al. (2019b).

Two representative pulse days were chosen to be studied in this paper. But, since the lifetime diurnal-pulse activity in a single storm has never been documented, this appendix will now detail the different types of diurnal pulses that occurred over Harvey's lifetime using azimuthally averaged IR brightness temperatures (Fig. A1a) and azimuthally averaged 6-h IR brightness temperatures differences (Fig. A1b) both with overlaying azimuthally summed WWLLN lightning flash data (hatched for values $\geq 25$ flashes). Azimuthal averages were computed using a $0.07^{\circ}$ bin size, matching the GridSat-B1 resolution, were sorted into bins centered on the hour, and were averaged.

Between 0000 LT 17 August and 2300 LT 21 August, Harvey experienced multiple expansions and contractions of cold cloud tops $\left(<-35^{\circ} \mathrm{C}\right)$ and lightning (Fig. A1a). The associated 6-h IR brightness temperature differences and lightning depict outward propagating cooler cloud tops (Fig. A1b) that the objective metrics identified as one INACT SLCP and four ACT LLCPs. It was not surprising that pulses were occurring when Harvey was a tropical storm and tropical depression, since Ditchek et al. (2019a) found that 
diurnal pulsing occurred on $46 \%$ and $24 \%$ of tropical storm and tropical depression days in the Atlantic basin, respectively. The largest magnitude and most radially extensive diurnal pulses, however, occurred on days where Harvey was designated as a low and as a tropical wave, storm classifications not included in Ditchek et al. (2019a). Given that lows and tropical waves are often not well organized, this was surprising.

On 22 August, Harvey traversed the Yucatan peninsula and weakened slightly. The $<-35^{\circ}$ cold cloud tops found on previous days were not present; yet, the objective metrics identified that an ACT LLCP occurred on that day, despite Harvey having made landfall.

One day later, Harvey entered the Gulf of Mexico and rapidly intensified to a category 4 hurricane by 2300 LT 25 August. ${ }^{\text {A1 }}$ Over this time period, outward propagating cooler cloud tops were present and the objective metrics identified that three ACT LLCPs occurred (Fig. A1b).

Harvey first made landfall on San Jose Island, Texas, at 0300 UTC 26 August and then $3 \mathrm{~h}$ later west of Holiday Beach, Texas. Afterward, Harvey rapidly weakened from a category 4 hurricane to a tropical storm in less than $12 \mathrm{~h}$. Harvey then stalled over, and just offshore of, the Texas coastline through 29 August before moving into the Gulf of Mexico and making its final landfall at 0800 UTC 30 August in Cameron, Louisiana. After its final landfall, Harvey weakened to a tropical depression and became an extratropical cyclone before dissipating over northern Kentucky on 2 September. While cold cloud tops of $<-35^{\circ} \mathrm{C}$ were no longer present in Harvey after rapidly weakening, between 0000 LT 26 August and 2300 LT 1 September, two ACT LLCPs, one QUASI LLCP, one QUASI SLCP, one ACT LLWP, one INACT LLWP, and one INACT SLWP occurred (Figs. A1a,b).

Thus, while this paper focused on documenting just two pulses present in Harvey, Harvey actually had pulses occurring each day. This is not surprising, as diurnal pulses have been found to be near-ubiquitous features of tropical cyclones, present $88 \%$ of the time. What was surprising, however, was that among the additional 14 pulses in this appendix, diurnal pules were found to occur in lows and tropical waves, as well as during and after tropical cyclone landfall-areas not included in the Ditchek et al. (2019a,b) climatologies, motivating the need for future research.

\footnotetext{
${ }^{\text {A1 }}$ Rapid intensification is defined as an increase in the maximum sustained winds of a tropical cyclone of $30 \mathrm{kt}$ in $24 \mathrm{~h}$ (Kaplan and DeMaria 2003; Kaplan et al. 2010).
}

\section{REFERENCES}

Abarca, S. F., K. L. Corbosiero, and T. J. Galarneau Jr., 2010: An evaluation of the Worldwide Lightning Location Network (WWLLN) using the National Lightning Detection Network (NLDN) as ground truth. J. Geophys. Res., 115, D18206, https://doi.org/10.1029/2009JD013411.

-, , and D. Vollaro, 2011: The World Wide Lightning Location Network and convective activity in tropical cyclones. Mon. Wea. Rev., 139, 175-191, https://doi.org/10.1175/ 2010MWR3383.1.

Alland, J. J., 2019: Synergistic effects of midlevel dry air and vertical wind shear on tropical cyclone development. Ph.D. thesis, University at Albany, State University of New York, Albany, NY, 221 pp.

Barnes, G., E. Zipser, D. Jorgensen, and F. Marks Jr., 1983: Mesoscale and convective structure of a hurricane rainband. J. Atmos. Sci., 40, 2125-2137, https://doi.org/10.1175/15200469(1983)040<2125:MACSOA > 2.0.CO;2.

Benjamin, S. G., and Coauthors, 2016: A North American hourly assimilation and model forecast cycle: The Rapid Refresh. Mon. Wea. Rev., 144, 1669-1694, https://doi.org/10.1175/ MWR-D-15-0242.1.

Blake, E. S., and D. A. Zelinsky, 2017: National Hurricane Center Tropical Cyclone Report: Hurricane Harvey (17 August-1 September 2017). Tech. Rep. AL092017, NOAA/National Hurricane Center, 77 pp., https://www.nhc.noaa.gov/data/tcr/ AL092017_Harvey.pdf.

Blaylock, B. K., J. D. Horel, and S. T. Liston, 2017: Cloud archiving and data mining of high-resolution rapid refresh forecast model output. Comput. Geosci., 109, 43-50, https://doi.org/ 10.1016/j.cageo.2017.08.005.

Corbosiero, K. L., and J. Molinari, 2002: The effects of vertical wind shear on the distribution of convection in tropical cyclones. Mon. Wea. Rev., 130, 2110-2123, https://doi.org/10.1175/ 1520-0493(2002)130<2110:TEOVWS>2.0.CO;2.

$\longrightarrow$, and -2003 : The relationship between storm motion, vertical wind shear, and convective asymmetries in tropical cyclones. J. Atmos. Sci., 60, 366-376, https://doi.org/10.1175/ 1520-0469(2003)060<0366:TRBSMV>2.0.CO;2.

- — — - A. R. Aiyyer, and M. L. Black, 2006: The structure and evolution of Hurricane Elena (1985). Part II: Convective asymmetries and evidence for vortex Rossby waves. Mon. Wea. Rev., 134, 3073-3091, https://doi.org/ 10.1175/MWR3250.1.

DeMaria, M., and J. Kaplan, 1994: A Statistical Hurricane Intensity Prediction Scheme (SHIPS) for the Atlantic basin. Wea. Forecasting, 9, 209-220, https://doi.org/10.1175/1520-0434(1994) 009<0209:ASHIPS $>2.0 . \mathrm{CO} ; 2$.

—-, and —_, 1999: An updated Statistical Hurricane Intensity Prediction Scheme (SHIPS) for the Atlantic and eastern North Pacific basins. Wea. Forecasting, 14, 326337, https://doi.org/10.1175/1520-0434(1999)014<0326:AUSHIP> 2.0.CO;2.

_- M. Mainelli, L. K. Shay, J. A. Knaff, and J. Kaplan, 2005: Further improvements to the Statistical Hurricane Intensity Prediction scheme (SHIPS). Wea. Forecasting, 20, 531-543, https://doi.org/10.1175/WAF862.1.

_ - R. T. DeMaria, J. A. Knaff, and D. Molenar, 2012: Tropical cyclone lightning and rapid intensity change. Mon. Wea. Rev., 140, 1828-1842, https://doi.org/10.1175/MWR-D-11-00236.1.

Demuth, J. L., M. DeMaria, and J. A. Knaff, 2006: Improvement of advanced microwave sounding unit tropical cyclone intensity 
and size estimation algorithms. J. Appl. Meteor. Climatol., 45, 1573-1581, https://doi.org/10.1175/JAM2429.1.

Didlake, A. C., and R. A. Houze, 2009: Convective-scale downdrafts in the principal rainband of Hurricane Katrina (2005). Mon. Wea. Rev., 137, 3269-3293, https://doi.org/10.1175/ 2009MWR2827.1.

Ditchek, S. D., J. Molinari, K. L. Corbosiero, and R. G. Fovell, 2019a: An objective climatology of tropical cyclone diurnal pulses in the Atlantic basin. Mon. Wea. Rev., 147, 591-605, https://doi.org/10.1175/MWR-D-18-0368.1.

— , K. L. Corbosiero, R. G. Fovell, and J. Molinari, 2019b: Electrically active tropical cyclone diurnal pulses in the Atlantic basin. Mon. Wea. Rev., 147, 3595-3607, https:// doi.org/10.1175/MWR-D-19-0129.1.

Dunion, J. P., C. D. Thorncroft, and C. S. Velden, 2014: The tropical cyclone diurnal cycle of mature hurricanes. Mon. Wea. Rev., 142, 3900-3919, https://doi.org/10.1175/MWR-D13-00191.1.

,-- , and D. S. Nolan, 2019: Tropical cyclone diurnal cycle signals in a hurricane nature run. Mon. Wea. Rev., 147, 363388, https://doi.org/10.1175/MWR-D-18-0130.1.

Evans, R. C., and D. S. Nolan, 2019: Balanced and radiating wave responses to diurnal heating in tropical cyclone-like vortices using a linear nonhydrostatic model. J. Atmos. Sci., 76, 25752597, https://doi.org/10.1175/JAS-D-18-0361.1.

Hawkins, J., and C. Velden, 2011: Supporting meteorological field experiment missions and postmission analysis with satellite digital data and products. Bull. Amer. Meteor. Soc., 92, 10091022, https://doi.org/10.1175/2011BAMS3138.1.

Hence, D. A., and R. A. Houze, 2008: Kinematic structure of convective-scale elements in the rainbands of Hurricanes Katrina and Rita (2005). J. Geophys. Res., 113, D15108, https://doi.org/10.1029/2007JD009429.

Houze, R. A., 2010: Clouds in tropical cyclones. Mon. Wea. Rev., 138, 293-344, https://doi.org/10.1175/2009MWR2989.1.

James, E. P., and S. G. Benjamin, 2017: Observation system experiments with the hourly updating rapid refresh model using GSI hybrid ensemble-variational data assimilation. Mon. Wea. Rev., 145, 2897-2918, https://doi.org/10.1175/MWR-D16-0398.1.

Kaplan, J., and M. DeMaria, 2003: Large-scale characteristics of rapidly intensifying tropical cyclones in the North Atlantic basin. Wea. Forecasting, 18, 1093-1108, https://doi.org/10.1175/ 1520-0434(2003)018<1093:LCORIT>2.0.CO;2.

,-- , and J. A. Knaff, 2010: A revised tropical cyclone rapid intensification index for the Atlantic and eastern North Pacific basins. Wea. Forecasting, 25, 220-241, https://doi.org/10.1175/ 2009WAF2222280.1.

Knapp, K. R., and Coauthors, 2011: Globally gridded satellite observations for climate studies. Bull. Amer. Meteor. Soc., 92, 893-907, https://doi.org/10.1175/2011BAMS3039.1.

Landsea, C. W., and J. L. Franklin, 2013: Atlantic hurricane database uncertainty and presentation of a new database format. Mon. Wea. Rev., 141, 3576-3592, https://doi.org/10.1175/ MWR-D-12-00254.1.

Li, Q., and Y. Wang, 2012a: A comparison of inner and outer spiral rainbands in a numerically simulated tropical cyclone. Mon. Wea. Rev., 140, 2782-2805, https://doi.org/10.1175/MWR-D11-00237.1.

, and $-2012 \mathrm{~b}$ : Formation and quasi-periodic behavior of outer spiral rainbands in a numerically simulated tropical cyclone. J. Atmos. Sci., 69, 997-1020, https://doi.org/10.1175/ 2011JAS3690.1.
,-- , and Y. Duan, 2017: A numerical study of outer rainband formation in a sheared tropical cyclone. J. Atmos. Sci., 74, 203-227, https://doi.org/10.1175/JAS-D-16-0123.1.

Montgomery, M. T., and R. J. Kallenbach, 1997: A theory for vortex Rossby-waves and its application to spiral bands and intensity changes in hurricanes. Quart. J. Roy. Meteor. Soc., 123, 435-465, https://doi.org/10.1002/qj.49712353810.

Moon, Y., and D. S. Nolan, 2015a: Spiral rainbands in a numerical simulation of Hurricane Bill (2009). Part I: Structures and comparisons to observations. J. Atmos. Sci., 72, 164-190, https://doi.org/10.1175/JAS-D-14-0058.1.

$\longrightarrow$, and $-2015 \mathrm{~b}$ : Spiral rainbands in a numerical simulation of Hurricane Bill (2009). Part II: Propagation of inner rainbands. J. Atmos. Sci., 72, 191-215, https://doi.org/10.1175/JASD-14-0056.1.

Navarro, E. L., G. J. Hakim, and H. E. Willoughby, 2017: Balanced response of an axisymmetric tropical cyclone to periodic diurnal heating. J. Atmos. Sci., 74, 3325-3337, https://doi.org/ 10.1175/JAS-D-16-0279.1.

Nguyen, L. T., J. Molinari, and D. Thomas, 2014: Evaluation of tropical cyclone center identification methods in numerical models. Mon. Wea. Rev., 142, 4326-4339, https://doi.org/ 10.1175/MWR-D-14-00044.1.

Nolan, D. S., R. Atlas, K. T. Bhatia, and L. R. Bucci, 2013: Development and validation of a hurricane nature run using the joint OSSE nature run and the WRF model. J. Adv. Model. Earth Syst., 5, 382-405, https://doi.org/10.1002/JAME.20031.

O'Neill, M. E., D. Perez-Betancourt, and A. A. Wing, 2017: Accessible environments for diurnal-period waves in simulated tropical cyclones. J. Atmos. Sci., 74, 2489-2502, https:// doi.org/10.1175/JAS-D-16-0294.1.

Powell, M. D., 1990a: Boundary layer structure and dynamics in outer hurricane rainbands. Part I: Mesoscale rainfall and kinematic structure. Mon. Wea. Rev., 118, 891-917, https:// doi.org/10.1175/1520-0493(1990)118<0891: BLSADI $>2.0 . \mathrm{CO} ; 2$.

_ 1990b: Boundary layer structure and dynamics in outer hurricane rainbands. Part II: Downdraft modification and mixed layer recovery. Mon. Wea. Rev., 118, 918-938, https://doi.org/ 10.1175/1520-0493(1990)118<0918:BLSADI >2.0.CO;2.

Reasor, P. D., M. T. Montgomery, F. D. Marks Jr., and J. F. Gamache, 2000: Low-wavenumber structure and evolution of the hurricane inner core observed by airborne dual-Doppler radar. Mon. Wea. Rev., 128, 1653-1680, https://doi.org/10.1175/ 1520-0493(2000)128<1653:LWSAEO > 2.0.CO;2.

Rodger, C. J., J. B. Brundell, R. H. Holzworth, and E. H. Lay, 2009: Growing detection efficiency of the World Wide Lightning Location Network. AIP Conf. Proc., 1118, 15-20, https:// doi.org/10.1063/1.3137706.

Rozoff, C. M., W. H. Schubert, B. D. McNoldy, and J. P. Kossin, 2006: Rapid filamentation zones in intense tropical cyclones. J. Atmos. Sci., 63, 325-340, https://doi.org/10.1175/ JAS3595.1.

Ruppert, J. H., and M. E. O'Neill, 2019: Diurnal cloud and circulation changes in simulated tropical cyclones. Geophys. Res. Lett., 46, 502-511, https://doi.org/10.1029/2018GL081302.

Simpson, R. H., 1974: The hurricane disaster potential scale. Weatherwise, 27, 169-186, https://doi.org/10.1080/ 00431672.1974.9931702.

Stevenson, S. N., K. L. Corbosiero, and S. F. Abarca, 2016: Lightning in eastern North Pacific tropical cyclones: A comparison to the North Atlantic. Mon. Wea. Rev., 144, 225-239, https://doi.org/10.1175/MWR-D-15-0276.1. 
M. DeMaria, and J. L. Vigh, 2018: A 10-year survey of tropical cyclone inner-core lightning bursts and their relationship to intensity change. Wea. Forecasting, 33, 23-36, https://doi.org/10.1175/WAF-D-17-0096.1.

Wu, W.-S., R. J. Purser, and D. F. Parrish, 2002: Three-dimensional variational analysis with spatially inhomogeneous covariances. Mon. Wea. Rev., 130, 2905-2916, https://doi.org/10.1175/ 1520-0493(2002)130<2905:TDVAWS>2.0.CO;2.
Yu, C.-K., and C.-L. Tsai, 2013: Structural and surface features of arc-shaped radar echoes along an outer tropical cyclone rainband. J. Atmos. Sci., 70, 56-72, https://doi.org/10.1175/ JAS-D-12-090.1.

, C.-Y. Lin, L.-W. Cheng, J.-S. Luo, C.-C. Wu, and Y. Chen, 2018: The degree of prevalence of similarity between outer tropical cyclone rainbands and squall lines. Sci. Rep., 8, 8247, https://doi.org/10.1038/s41598-018-26553-8. 